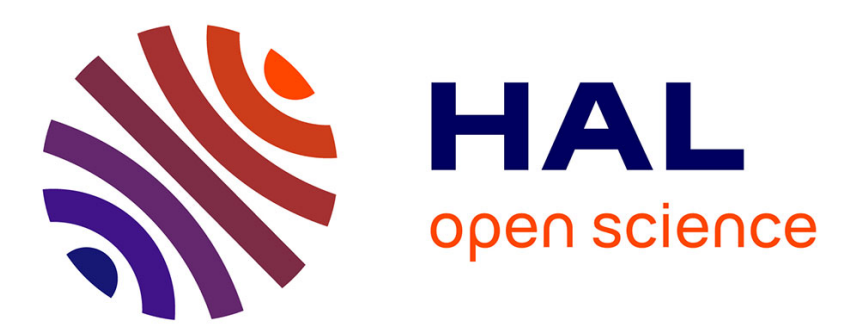

\title{
A minimal model for hepatic fatty acid balance during fasting: Application to PPAR alpha-deficient mice
} Pierre Blavy, Florence Gondret, Hervé Guillou, Sandrine Lagarrigue, P.G.P. Martin, Jaap J. van Milgen, Ovidiu Radulescu, A. Siegel

\section{- To cite this version:}

Pierre Blavy, Florence Gondret, Hervé Guillou, Sandrine Lagarrigue, P.G.P. Martin, et al.. A minimal model for hepatic fatty acid balance during fasting: Application to PPAR alpha-deficient mice. Journal of Theoretical Biology, 2009, 261 (2), pp.266. 10.1016/j.jtbi.2009.07.025 . hal-00559147

\section{HAL Id: hal-00559147 \\ https://hal.science/hal-00559147}

Submitted on 25 Jan 2011

HAL is a multi-disciplinary open access archive for the deposit and dissemination of scientific research documents, whether they are published or not. The documents may come from teaching and research institutions in France or abroad, or from public or private research centers.
L'archive ouverte pluridisciplinaire HAL, est destinée au dépôt et à la diffusion de documents scientifiques de niveau recherche, publiés ou non, émanant des établissements d'enseignement et de recherche français ou étrangers, des laboratoires publics ou privés. 


\section{Author's Accepted Manuscript}

A minimal model for hepatic fatty acid balance during fasting: Application to PPAR alpha-deficient mice*

P. Blavy, F. Gondret, H. Guillou, S. Lagarrigue, P.G.P. Martin, J. van Milgen, O. Radulescu, A. Siegel

PII:

S0022-5193(09)00331-2

DOI: doi:10.1016/j.jtbi.2009.07.025

Reference: YJTBI 5636

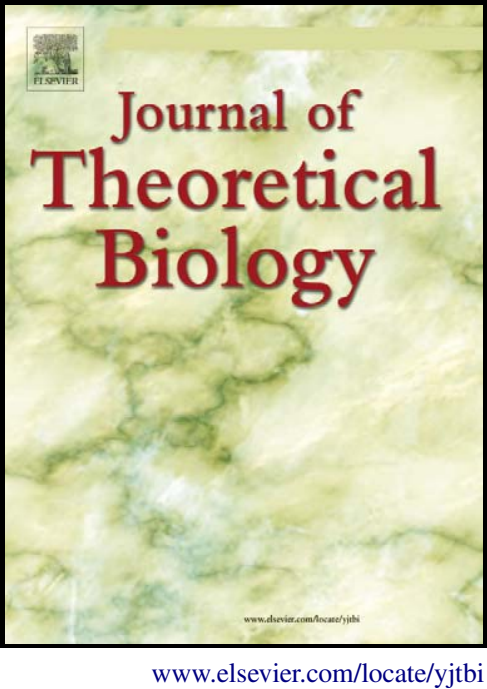

To appear in: $\quad$ Journal of Theoretical Biology

Received date: $\quad 21$ March 2009

Revised date: $\quad 25$ June 2009

Accepted date: $\quad 16$ July 2009

Cite this article as: P. Blavy, F. Gondret, H. Guillou, S. Lagarrigue, P.G.P. Martin, J. van Milgen, O. Radulescu and A. Siegel, A minimal model for hepatic fatty acid balance during fasting: Application to PPAR alpha-deficient mice*, Journal of Theoretical Biology, doi:10.1016/j.jtbi.2009.07.025

This is a PDF file of an unedited manuscript that has been accepted for publication. As a service to our customers we are providing this early version of the manuscript. The manuscript will undergo copyediting, typesetting, and review of the resulting galley proof before it is published in its final citable form. Please note that during the production process errors may be discovered which could affect the content, and all legal disclaimers that apply to the journal pertain. 


\title{
A minimal model for hepatic fatty acid balance during fasting: application to PPAR alpha-deficient mice*
}

\author{
P. Blavy ${ }^{\mathrm{a}, \mathrm{g}}$, F. Gondret ${ }^{\mathrm{a}}$, H. Guillou ${ }^{\mathrm{b}}$, S. Lagarrigue ${ }^{\mathrm{c}, \mathrm{d}, \mathrm{e}}$, P. G. P. Martin ${ }^{\mathrm{b}}$, \\ J. van Milgen ${ }^{\mathrm{a}}$, O. Radulescu* ${ }^{* * \mathrm{~h}, \mathrm{~g}}$, A. Siegel ${ }^{\mathrm{f}, \mathrm{g}}$ \\ ${ }^{a}$ INRA, UMR1079 Systèmes d'Elevage, Nutrition Animale et Humaine (SENAH), \\ F-35590 Saint Gilles, France \\ ${ }^{b}$ INRA, UR66 Laboratoire de Pharmacologie et Toxicologie, \\ 180 Chemin de Tournefeuille, BP3, F-31931 Toulouse cedex 9, France \\ ${ }^{c}$ Agrocampus Ouest, UMR 598 Génétique Animale, F-35000 Rennes, France \\ ${ }^{d}$ INRA, UMR 598 Génétique Animale, F-35000 Rennes, France \\ IFR 140, GFAS, F-35000 Rennes, France \\ ${ }^{f}$ CNRS, UMR 6074 IRISA, \\ Campus de Beaulieu, F-35042 Rennes, France \\ ${ }^{g}$ INRIA Rennes Bretagne Atlantique, Symbiose-project, \\ Campus de Beaulieu, F-35041 Rennes, France \\ ${ }^{h}$ Université de Rennes 1, UMR 6625 IRMAR, \\ Campus de Beaulieu, F-35042 Rennes, France
}

\section{Abstract}

The purpose of this study is to identify the hierarchy of importance amongst pathways involved in fatty acid (FA) metabolism and their regulators in the control of hepatic FA composition. A modeling approach was applied to experimental data obtained during fasting in PPAR $\alpha$-knockout (KO) mice and wild-type mice. A step-by-step procedure was used in which a very simple model was completed by additional pathways until the model fitted correctly the measured quantities of FA in the liver. The resulting model included FA uptake by the liver, FA oxidation, elongation and elongation and desaturation of FA, which were found active in both genotypes during fasting.

From the model analysis we concluded that PPAR $\alpha$ had a strong effect on FA oxidation. There were no indications that this effect changes during the fasting period, and it was thus considered to be constant.

In PPAR $\alpha$ KO mice, FA uptake was identified as the main pathway responsible for FA variation in the liver. The models showed that FA were oxidized

Email addresses: pierre.blavy@irisa.fr (P. Blavy),

florence.gondret@rennes.inra.fr (F. Gondret), Herve.Guillou@toulouse.inra.fr

(H. Guillou), Sandrine.Lagarrigue@agrocampus-ouest.fr (S. Lagarrigue),

Pascal.Martin@toulouse.inra.fr (P. G. P. Martin), jaap.vanmilgen@rennes.inra.fr

(J. van Milgen), ovidiu.radulescu@inria.fr (O. Radulescu**), anne.siegel@irisa.fr

(A. Siegel)

* Results were partially presented at the JOBIM-2008 meeting held in Lille, France.

** Corresponding Author : IRISA, Campus de Beaulieu . F-35 042 Rennes Cedex FRANCE. Tel.: +33 299847306; fax: +33 299847171. 
at a constant and small rate, whereas elongation and desaturation of FA also occurred during fasting.

The latter observation was rather unexpected, but was confirmed experimentally by the measurement of delta-6-desaturase mRNA using real-time quantitative PCR (QPCR). These results confirm that mathematical models can be a useful tool in identifying new biological hypotheses and nutritional routes in metabolism.

Key words: fatty acid metabolism, systems biology, fasting, knockout mice, modelling.

\section{Introduction}

Fatty acids (FA) are the main constituents of lipids in the body and are building blocks for glyco- and phospholipids of cell membranes. FA also play an important role in energy metabolism, allowing the storage of energy in a very dense form as triglycerides, which can be oxidized later when energy is needed. The FA can also act as signaling molecules and behave as regulators of several transcription factors (Duplus et al., 2000). Therefore, they play crucial roles in normal growth and development (e.g., (Uauy et al., 2007)) but also in coronary artery disease (Seidelin, 1995; Shirai, 2004), dyslipidemia, hepatic steatosis and other pathologies (Seidelin, 1995; Simopoulos, 1991).

The balance between synthesis and degradation of FA is regulated by nutrient supply and the energy needs of the organism. In humans and mice, the liver plays a central role in the endogenous synthesis of FA (Muiruri and Leveille, 1970). During fasting, FA are released from adipose tissue (AT) by lipolysis, and serve as sources of energy in other organs. Circulating free FA are extensively taken up by the liver in fasting rodents (Remesy and Demigne, 1983). In the liver, FA can be a source of substrates for the synthesis of ketone bodies ketone, which can be used as fuel by extrahepatic tissues.

The synthesis, degradation, and transformation of FA in hepatic cells are catalyzed by over 300 enzymatic reactions (Kanehisa et al., 2008) involved in distinct pathways (e.g., FA oxidation and elongation). These reactions are regulated at the metabolic and genetic levels by various hormones (e.g., insulin (Campbell et al., 1992), leptin (Unger et al., 1999)) and nutrients (e.g., poly unsaturated FA (Sessler and Ntambi, 1998)). However, the simple aggregation of abundant literature data cannot account for all underlying interactions responsible for both FA metabolism and lipid phenotype. A better and more comprehensive understanding of FA metabolism is needed to identify routes that will allow for the nutritional modulation of lipid deposition that may help preventing or curing lipid-related disorders. Therefore, it is critical to identify the main pathways and regulators involved in the control of FA metabolism. To achieve this goal, we used a modelling approach.

Mathematical models are powerful tools to combine information using a common formalism. Models are frequently used to describe, predict and test hypotheses. Depending on the objective, models can have different levels of detail, 
ranging from very basic molecular mechanisms (e.g., (Fattal and Ben-Shaul, 1993)) to an empirical "black box" approach (e.g., (Forns et al., 2002)). Models can be useful to explore and better understand FA metabolism and its regulation within a cell, as well as between organs involved in lipid metabolism. To provide a full description of the dynamics of the system considered as a homogeneous organ (e.g., (Calvetti et al., 2008)) or including the heterogeneous nature of the organ (e.g., spatial models (Chalhoub et al., 2007b)), metabolic reactions are modeled as differential equations or analyzed by convex optimization techniques such as flux balance analysis. Spatial models typically use partial differential equations.

A contrasted situation is necessary to identify the key mechanisms involved in the regulation of FA metabolism. In the present study, we considered the kinetics of FA metabolism during fasting in both wild-type and peroxisome proliferator-activated receptor alpha $(\mathrm{PPAR} \alpha)$ knockout $(\mathrm{KO})$ mice. Fasting triggers complex adaptive metabolic responses, including a switch to rely on FA and ketone bodies for ATP synthesis ((Leone et al., 1999)) and an increased capacity for mitochondrial FA oxidation in tissues with high energy demands (Hashimoto et al., 2000; Leone et al., 1999). The PPAR $\alpha$ is considered as the master regulator of FA homeostasis (Desvergne and Wahli, 1999; Leone et al., 1999). A genome-wide transcriptomic approach in mice has recently pointed out the role of PPAR $\alpha$ in the liver in the regulation of FA oxidation and ketone body production during fasting (Sokolović et al., 2008). Animals lacking $\operatorname{PPAR} \alpha$ appear to be unable to increase the capacity for cellular FA utilization (Leone et al., 1999). Monitoring the variation in FA composition in tissues of wild-type and PPAR $\alpha \mathrm{KO}$ mice during fasting provides a useful experimental data set to understand the regulation of FA metabolism and to develop computational models describing this metabolism.

To our knowledge, there is only one model (Chalhoub et al., 2007a) focused on lipid metabolism in the liver during fasting conditions. This detailed mathematical model was based on differential equations and simulated gluconeogenesis during a 24-h fasting period in the perfused rat liver. This model included key reactions for FA metabolism such as FA uptake, synthesis of triglycerides, and FA oxidation. Because of the large number of reactions involved, many of these were aggregated in series. Moreover, this model did not intend to predict the variation in FA composition in the liver and did not include the genetic regulation of FA metabolism. It intended to predict concentrations and fluxes of intermediate metabolites involved in FA metabolism and gluconeogenesis in response to changes in various substrate concentrations in the perfused liver.

The aim of the present study was to identify the most relevant pathways and their regulators involved in hepatic FA metabolism. Based on experimental data and information from the literature, a model (based on differential equations) was developed that allows to explain the variation in FA composition of the mouse liver during a fed-to-fasting transition. Additional experimental measurements (mRNA expression of delta-6-desaturase, a key enzyme of polyunsaturated FA synthesis) were carried out to evaluate hypotheses that were formulated following model analyses. 


\section{Materials and methods}

\subsection{Biological experiments}

\subsubsection{Experimental data}

Experimental data were obtained in 8 week-old male wild-type C57BL/6J (WT) and PPAR $\alpha$ KO mice (Lee et al., 1995; Costet et al., 1998) over a 72 $\mathrm{h}$ fasting period. Three to 6 mice for each genotype were sacrificed at different times points $(0,3,6,9,12,18,24,36,48,60,72 \mathrm{~h})$ after the last meal. Before fasting, all animals were fed ad libitum a rodent diet 2018 from Harlan Teklad (Gannat, France). At each time point, animal body weight was recorded and liver and epididymal White Adipose tissue (AT) were dissected, weighed, frozen in liquid nitrogen immediately after dissection, and stored at $-80^{\circ} \mathrm{C}$ until analysis. Total lipid content was determined in liver and AT as described previously (Martin et al., 2007). Proportions of individual FA were determined by gas chromatography analysis of FA methyl esters. The quantities of each FA

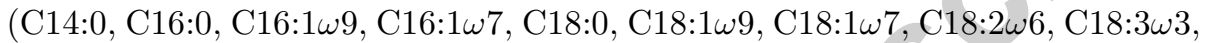
$\mathrm{C} 20: 1 \omega 9, \mathrm{C} 20: 3 \omega 6, \mathrm{C} 20: 4 \omega 6, \mathrm{C} 20: 5 \omega 3, \mathrm{C} 22: 6 \omega 3)$ in the liver and AT were calculated considering the relative proportions of FA in total lipids and the mass of liver and AT. Time-related variations in FA quantity were analyzed using the $\operatorname{lm}$ () linear regression implemented in R 2.8.1 (www.r-project.org).

\subsubsection{Gene expression}

Hepatic total RNA was extracted using Trizol reagent (Invitrogen) according to the manufacturer's instruction. Complementary cDNA was synthesized from $2 \mu \mathrm{g}$ of total RNA using random primers and Superscript II (Invitrogen) reverse transcriptase according to the manufacturer's instructions. The mRNA levels of Delta6 desaturase (D6D) were measured by quantitative real-time PCR (QPCR) after $0,24,48$, and $72 \mathrm{~h}$ of fasting using 3'-TCCAGTACCAGATCATCATGACAA-5' as forward primer and 3'-GGTGTAGAAGAAACGCATATAGTAGCTG-5' as reverse primer. Amplifications were performed on an ABI Prism 7000 Sequence Detection System (Applied Biosystems, Courtaboeuf, France).

The QPCR data were normalized by TATA-box binding protein (TBP) expression levels (TBP-F: ACTTCGTGCAAGAAATGCTGAA, TBP-R: GCAGTTGTCCGTGGCTCTCT) and analyzed using the DART-PCR software (Peirson et al., 2003).

\subsection{Principles of model development}

A step-by-step procedure was applied to include different metabolic pathways and regulators until the model fitted the data well and no reasonable improvement could be obtained.

Due to the absence of at least one complex regulatory system, the PPAR $\alpha$ $\mathrm{KO}$ mice can be considered as a relatively simpler model compared to wildtype mice. Therefore we first fitted the successive models on data obtained in $\operatorname{PPAR} \alpha$ KO mice. In order to allow comparisons between genotypes within the same model (or modeling framework), we then extrapolated to wild-type mice 
the values of the parameters that should be common to both genotypes. We consider that the $\mathrm{KO}$ mice is just a simpler and easier to study submodel of the wild type model. This resulted in a minimal model of a set of ordinary differential equations describing FA metabolism in the liver(Table 1).

The main pathways used in our model of FA metabolism are consistent with common biochemistry knowledge (Kanehisa et al., 2008; Murray et al., 2006), and include (Fig. 1) FA uptake, FA oxidation in mitochondria and peroxisomes, ketogenesis, the tricarboxylic acid cycle (where ATP is produced from acetyl-coA), synthesis of malonyl-CoA from acetyl-coA, synthesis of palmitic acid (C16:0) from malonyl-CoA and acetyl-coA, glycolysis to produce acetylcoA from glucose, and elongation and desaturation of polyunsaturated FA.

Several key regulators of FA metabolism have been described in the literature. They include $\operatorname{PPAR} \alpha$, which is a transcription factor that activates FA oxidation (Leone et al., 1999; Desvergne and Wahli, 1999; Lee et al., 1995) and FA elongation and desaturation (Wang et al., 2006; Guillou et al., 2002). Other regulators are SREBP1, which is a transcription factor that activates FA synthesis (Horton et al., 2002; Jakobsson et al., 2006) as well as FA elongation and desaturation (Matsuzaka et al., 2002) and malonylCoA, which inhibits FA oxidation.

Because of the experimental conditions and the resulting data in the present study, a decision was made as to which variables should be included in the model. Metabolic pathways and regulators that were supposed to be inactive or constant during fasting were not considered (Fig. 1). During the early hours of fasting ( 3 to $6 \mathrm{~h}$ ), the level of SREBP1 markedly decreases in the liver (Horton et al., 1998), which results in a fasting-mediated transcriptional downregulation of the gene encoding FA synthase (i.e., the key enzyme of de novo FA synthesis (Shimano et al., 1999; Horton et al., 2002; Kim et al., 1998)). Therefore, SREBP1 was assumed to be negligible in our experimental conditions, and de novo FA synthesis was supposed not to occur in our experimental conditions. Hence, the influence of SREBP1 on elongation and desaturation was not considered. Moreover, since malonylCoA is an intermediate in de novo FA synthesis, the malonylCoA-dependent inhibition of mitochondrial FA uptake was not considered. Acetyl-coA is a pivot in intermediary metabolism between catabolic and anabolic processes (van Milgen, 2002). However, because the quantity of acetyl-coA has no direct effect on the FA composition in the liver, there was no need to consider the 3 pathways affecting acetyl-coA (i.e., glycolysis, ketogenesis and the tricarboxylic acid cycle).

\subsection{Model description}

\subsubsection{Choice of variables}

In the various models we considered, we included all measured metabolites, except those involved in intermediate metabolism (i.e. molecules participating in a considered reaction that are neither a product nor a substrate). Therefore,

when the elongation and desaturation pathway was added, we included the sum of $S \omega 3=C 20: 5 \omega 3+C 22: 6 \omega 3$ and $S \omega 6=C 20: 3 \omega 6+C 20: 4 \omega 6$ and not 
the individual quantities of $\mathrm{C} 20: 5 \omega 3$ and $\mathrm{C} 20: 3 \omega 6$, which were considered as intermediates. Individual quantities of other FA were included in the model.

The quantity of PPAR $\alpha$ was not explicitly included as a variable in the model. However, the difference in numerical values of model parameters between wild-type and $\operatorname{PPAR} \alpha$ mice represent the effect of PPAR $\alpha$.

\subsubsection{Fluxes}

Liver uptake. Uptake of FA in the liver from the blood was difficult to assess in the experiments. During fasting, free FA are released from AT by lipolysis and serve as energy sources for other organs including the liver. We considered that the observed variation in FA composition in $\mathrm{AT}$ would reflect the FA uptake by the liver. Input fluxes of individual FA in liver $\left(\Phi_{i}^{i n}\right)$ were thus considered to be proportional to FA released from AT by lipolysis during fasting. The parameter $K_{\text {In }}$ represents the proportionality factor relating FA release from AT to FA uptake by the liver. The $K_{\text {In }}$ was supposed to be the same for all FA. During fasting, FA are released at a time-constant rate from AT that differs between FA. To evaluate this rate, a linear regression for each FA in AT $\left(X_{i}^{A T}\right)$ was performed as $X_{i}^{A T}=a_{i} *$ time + intercept $_{i}$. The slope $\left(a_{i}\right)$ of this relation was then used to estimate FA uptake by the liver:

$$
\Phi_{i}^{i n}=K_{I n} * a_{i}
$$

Oxidation. The reaction flux for total oxidation $\left(\Phi_{i}^{O x i}\right)$ of the $i$ th FA in the liver $\left(X_{i}^{L}\right)$ during fed-to-fast transition was expressed as a Michaelis-Menten equation in simplified form, using a constant parameter representing the oxidation rate $\left(k_{o x i}\right)$ and a relative affinity parameter for each FA $\left(b_{i}\right)$ :

$$
\Phi_{i}^{O x i}=k_{o x i} \frac{X_{i}^{L} b_{i}}{\sum_{j} X_{j}^{L} b_{j}} \text { with } \sum_{i} b_{i}=1
$$

We hypothesized that the quantities of FA were not limiting for the reaction. This assumption was supported by the fact that the sum of FA in the liver increased from 0 to $72 \mathrm{~h}$ since the onset of fasting (Table 2).

The FA do not always undergo complete oxidation resulting in acetyl-coA and ATP. Consequently, shorter-chain FA intermediates may be generated, which can accumulate in the liver. We considered incomplete oxidation of a FA as the reaction producing a FA that is two carbons shorter than the original FA. Therefore, the total oxidation flux $\Phi_{i}^{O x i}$ was separated into 2 fluxes representing either complete $\left(\Phi_{i}^{\text {CompleteOxi }}\right)$ or incomplete $\left(\Phi_{i}^{\text {IncompleteOxi }}\right)$ oxidation fluxes:

$$
\begin{gathered}
\Phi_{i}^{\text {CompleteOxi }}=s_{i} * \Phi_{i}^{O x i} \\
\Phi_{i}^{\text {IncompleteOxi }}=\left(1-s_{i}\right) * \Phi_{i}^{O x i},
\end{gathered}
$$

where $s_{i}$ represents the proportion of complete oxidation of the total oxidation.

In the models considered (Table 1), we had to choose between three hypotheses : the $i$ th FA is only oxidized completely $\left(s_{i}=1\right)$, the $i$ th FA is only partially 
oxidized leading to the generation of a two carbons shorter FA $\left(s_{i}=0\right)$, or the $i$ th FA is both partially and totally oxidized $\left(s_{i} \in\right] 0 ; 1[)$. These hypotheses will be tested going from the simplest $\left(s_{i}=1\right)$ to the most complicated hypothesis $\left(s_{i} \in\right] 0 ; 1[)$ in a step-by-step procedure (section 2.3.3). As will be shown later, the third hypothesis was not necessary to obtain a correct fit of the model to the data.

Elongation and desaturation. Unsaturated FA consist of monounsaturated and polyunsaturated FA. Based on the location of the last double bound, polyunsaturated FA are classified as $\omega 3$ or $\omega 6$. Within each class, FA can be transformed through elongation and desaturation reactions (Fig. 2). The enzyme D6D has been considered a rate-limiting enzyme (Cho et al., 1999) of the FA elongation/desaturation pathway, which coincide with the observation that hepatic quantities of $\mathrm{C} 18: 2 \omega 6$ and $\mathrm{C} 18: 3 \omega 3$ increased from 0 to $72 \mathrm{~h}$ of fasting (Table 2). Because D6D is common to $\omega 3$ and $\omega 6$ desaturation pathways, C18:2 $\omega 6$ and $\mathrm{C} 18: 3 \omega 3$ are in competition for this enzyme. Elongation and desaturation fluxes $\left(\Phi_{C 18: 2 \omega 6}^{\text {Desat }}\right.$ and $\left.\Phi_{C 18: 3 \omega 3}^{\text {Desat }}\right)$ of $\mathrm{C} 18: 2 \omega 6$ and $\mathrm{C} 18: 3 \omega 3$ were included in the rate of elongation and desaturation $\left(k_{\text {desat }}\right)$, and the relative affinity of $\mathrm{D} 6 \mathrm{D}$ for the $i$ th FA $\left(d_{i}\right)$ can be given as:

$$
\begin{gathered}
\Phi_{C 18: 3 \omega 3}^{\text {Desat }}=k_{\text {desat }} \frac{C 18: 3 \omega 3 * d_{C 18: 3 \omega 3}}{C 18: 3 \omega 3 * d_{C 18: 3 \omega 3}+C 18: 2 \omega 6 * d_{C 18: 2 \omega 6}} \\
\Phi_{C 18: 2 \omega 6}^{D e s a t}=k_{\text {desat }} \frac{C 18: 2 \omega 6 * d_{C 18: 2 \omega 6}}{C 18: 3 \omega 3 * d_{C 18: 3 \omega 3}+C 18: 2 \omega 6 * d_{C 18: 2 \omega 6}} \\
\text { with } \sum_{i} d_{i}=1 .
\end{gathered}
$$

\subsubsection{Choosing the optimal level of detail by a step-by-step procedure}

A step-by-step procedure was applied until the model included just enough detail to fit the change in FA quantities over time .

- Step 1: We started with a model including only one flux (i.e., uptake of FA from AT by the liver).

- Step 2: We estimated model parameters from the experimental data (see the parameter estimation method below).

- Step 3: If a parameter set was found allowing a close fit of model predictions to the observed data, the model (and its parameters) was accepted and the procedure ended (see the fitting criterion below). If not, model output was analyzed, and additional pathways and regulators were included. The selection of pathways and regulations was based on model behavior and biological knowledge. We then went back to step 2 .

Parameters estimation. An initial guess of parameter estimates was found by a linear approximation of the model under the assumption that $\sum_{j \in F A} X_{j}^{L} b_{j}$ is constant. This sum was evaluated by replacing $X_{j}^{L}$ by the mean of observed value for the $j$ th FA. Parameters were then estimated using the Nelder 
and Mead optimisation (Nelder and Mead, 1965) implemented in R 2.8.0 optim procedure, by minimizing the sum of squared deviations between observed data and predicted values.

Goodness of fit. Fitting quality was estimated using the coefficient of variation of the mean squared prediction error (cvMSPE) (Tedeschi, 2006; Bibby, 1977). The mean squared prediction error measures the distance between observed and predicted values, and can be decomposed in central error (CE), regression error (RE), and disturbance error (DE). The CE describes the contribution of distance between mean values of observed and predicted data. The RE describes how the slope of the linear regression between predicted and observed data differs from one. The DE is the remaining error. The cvMSPE was used to standardize the results, so that different FA could be compared. Models resulting in a low cvMSPE combined with an important contribution of DE are preferred and we considered results acceptable if $D E>25 \%$ (an arbitrarily chosen value).

\section{Results and discussion}

In both mouse genotypes, FA quantities in the liver were generally greater after a $72 \mathrm{~h}$ fasting period compared with the fed state (Table 2). For only three $\mathrm{FA}$, there was no difference in the quantity of FA between 0 and $72 \mathrm{~h}$. This

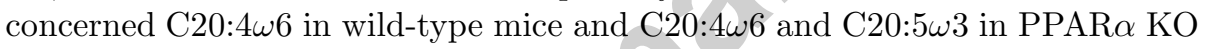
mice. There are indications in the literature showing that FA can accumulate in the liver during fasting in both PPAR $\alpha$ KO and wild-type mice using Sudan Black staining of lipids (Lee et al., 2004) or Oil Red O staining of neutral lipids (Hashimoto et al., 2000). The amplitudes of fasting-induced FA accumulations observed in the present study are consistent with a previous study of wild-type and PPARalpha knockout mice under the fed and starved (72h) conditions (see (Lee et al., 2004)).

This likely reflects the major role played by the liver during fasting to cope with the metabolism of FA coming from adipose tissue lipolysis. The quantities of most FA increased more markedely in PPAR $\alpha$ KO livers compared to wild-type controls (Table 2). As shown below, this likely results from the impared hepatic FA beta-oxidation in PPAR $\alpha$ KO mice. Saturated and especially monounsaturated FA were most strongly increased than polyunsaturated FA in both genotypes. Only C20:5w3 and C22:6w3 increased more strongly in wild-type than in PPAR $\alpha \mathrm{KO}$ livers during fasting (Table 2).

\subsection{Model structure}

According to the step-by-step procedure, three successive models were built, differing in degree of complexity. Model 1 included only FA uptake, whereas model 2 included both FA uptake and FA oxidation. Model 3 was similar to model 2 but also included elongation and desaturation of FA. The equations used for these models are given in Table 1. These models are shown in Figure 3. 
For each model, the values of the parameters were first estimated in the simpler PPAR $\alpha \mathrm{KO}$ mice model. The parameter values were then extrapolated to wild-type mice. When the model with extrapolated parameter values did not fit to the data for wild-type mice, then new parameter values were estimated from wild-type data (Table 3).

\subsection{Model 1: accumulation of FA by the liver}

This model included uptake of FA by the liver proportional to AT efflux. The proportionality constant was assumed to be the same for all FA. This constant was evaluated in $\operatorname{PPAR} \alpha \mathrm{KO}$ mice and then extrapolated to wild-type mice.

\subsubsection{During fasting, FA release from AT differs between genotypes}

Fatty acid composition in mouse liver (Table 2) and AT (Table 4) in the fed state was different in $\operatorname{PPAR} \alpha \mathrm{KO}$ mice than in wild-type mice. The FA quantities (except for $\mathrm{C} 20: 5 \omega 3$ and $\mathrm{C} 22: 6 \omega 3$ ) were generaly greater in the liver and lower (except for $\mathrm{C} 18: 2 \omega 6$ and $\mathrm{C} 18: 3 \omega 3$ ) in AT of $\mathrm{KO}$ mice compared with the wild-type mice. The variation in FA quantities in AT during fasting could be described by linear functions of time, as shown by the high correlation coefficients in Table 4. The regression slopes (Table 4) were lower in PPAR $\alpha$ KO mice than in WT animals, suggesting that lipolysis from AT was less active during fasting in the absence of $\operatorname{PPAR} \alpha$.

A lesser reduction in epididymal fat pad weights in $\mathrm{KO}$ mice compared with wild-type has been observed by others (Lee et al., 2004), suggesting that mobilization of fat depots is delayed during starvation in mice that lack PPAR $\alpha$.

This potential effect of PPAR $\alpha$ on adipose tissue lipolysis during fasting contrasts with its low expression in this tissue (Bookout et al., 2006). However, it has been shown that despite a low expression level PPAR $\alpha$ regulates glycerol kinase (GyK) in white adipose tissue (Mazzucotelli et al., 2007). Interestingly, PPAR $\alpha$ KO mice exhibit a higher basal AT Gyk expression compared to wild-type mice (Mazzucotelli et al., 2007). Since GyK is involved in FA recycling, its activity may contribute to counteract the effect of lipolysis in $\operatorname{PPAR} \alpha \mathrm{KO}$ AT. On the other hand, $\operatorname{PPAR} \alpha$-dependent regulations in other tissues expressing PPAR $\alpha$ could have indirect effects on AT through interorgan communications. For example, it has been proposed that PPAR $\alpha$ may regulate specific genes in the brain which could could result in increased Glut4 expression in the AT (Knauf et al., 2006). In this study, high Glut4 expression was proposed to increase glucose clearance in the adipose tissue of $\operatorname{PPAR} \alpha \mathrm{KO}$ mice thus contributing to their hypoglycemia during fasting. Increased glucose input in adipose tissue of fasted $\operatorname{PPAR} \alpha \mathrm{KO}$ mice may also contribute to counteract the effects of lipolysis on AT lipid content by stimulating inappropriately FA synthesis. 


\subsubsection{During fasting, FA hepatic input flux is assumed to be proportional to the $F A$ release from $A T$}

During fasting, FA released by lipolysis in AT serve as an energy source for other organs, including the liver. The free FA uptake by the liver has been described by others as a linear function of the total free FA concentration in blood (Berk and Stump, 1999), until saturation of the uptake system (Sorrentino and Berk, 1993).

In the absence of information in our experiments on the free FA flux in blood (i.e., FA concencentrations and blood flow), we assumed that hepatic input flux of FA was proportional to the FA release from AT during fasting, using a same $K_{\text {In }}$ proportionality constant for all FA and both genotypes.

3.2.3. FA uptake is the major phenomenon involved in the variation of FA in PPAR K KO mice, but not in wild-type mice where oxidation is important too

The cvMSPE estimates (Table 5) showed that the sum of all FA and all individual FA quantities except $\mathrm{C} 16: 1 \omega 7, \mathrm{C} 16: 1 \omega 9, \mathrm{C} 22: 6 \omega 3$, and $\mathrm{C} 18: 3 \omega 3$ were correctly fitted in PPAR $\alpha$ KO mice. By contrast, in wild-type mice neither the sum nor the individual FA are correctly fitted. This result was anticipated for wild-type mice, as during fasting, liver FA oxidation is known to be more active in wild-type mice than in PPAR $\alpha$ ones (Le May et al., 2000). Therefore, uptake of FA was the major phenomenon involved in the variation of hepatic FA during fasting in PPAR $\alpha \mathrm{KO}$ mice, but not in wild-type mice.

\subsubsection{Hepatic FA input can be modeled as a simple proportional function of FA variation in $A T$}

The good fitting of most FA in PPAR $\alpha$ KO mice confirmed that hepatic FA input can be modeled as a simple proportional function of FA variation in AT. This also suggests that FA uptake is the main pathway responsible for variation in hepatic FA composition in $\operatorname{PPAR} \alpha \mathrm{KO}$ mice during the fed-to-fasting transition. It also suggests that selective importation of FA was negligible.

\subsubsection{C16:1w7 has a specific two times dynamic.}

The quantity of $\mathrm{C} 16: 1 \omega 7$ was poorly fitted in PPAR $\alpha \mathrm{KO}$ mice and was overestimated from 50 to $72 \mathrm{~h}$ (Fig. 5). The kinetics of $\mathrm{C} 16: 1 \mathrm{w} 7$ hepatic accumulation seems to follow a specific time pattern with accumulation from 0 to $50 \mathrm{~h}$, to remain constant thereafter. This pattern cannot be explained by importation or specific oxidation, which should have occurred at a constant rate during the fed-to-fasting transition. Recently, it was shown that $\mathrm{C} 16: 1 \omega 7$ can act as an AT-derived signal and has, unlike other FA, a systemic metabolic effect (Cao et al., 2008). It is possible that $\mathrm{C} 16: 1 \omega 7$ has a very specific metabolic fate and not only targets the liver but also other tissues such as muscle. This hypothesis remains to be explored further experimentally, and the lack-of-fit for $\mathrm{C} 16: 1 \omega 7$ was therefore not further addressed in our model. 
3.2.6. The bad fitting of $C 16: 1 \omega 9$ and C22:6w3 in PPAR $\alpha$ KO mice is unlikely to be explained by a specific FA uptake

The poor fitting of the quantities of $\mathrm{C} 16: 1 \omega 9$ and $\mathrm{C} 22: 6 \omega 3$ in the liver of $\operatorname{PPAR} \alpha \mathrm{KO}$ mice can be explained by specific higher rates of uptake or by reactions that produce these FA from other FA. Cellular uptake of FA as well as intracellular transport of FA is mediated through simple diffusion, facilitated diffusion, or carrier-mediated transport (Berk and Stump, 1999). It has been shown (Oikari et al., 2008) that cytosolic acyl-carrier binding protein (ACBP) has a higher affinity for C14-C22 FA than for medium chain FA (C8-C12). To our knowledge, selective regulation of long-chain FA uptake has not yet been described. When we calculate the selective uptake for $\mathrm{C} 16: 1 \omega 9$, and $\mathrm{C} 22: 6 \omega 3$ required to fit the data, it appears that these values should have been 2 to 12 times greater than the common rate determined for the other FA. Therefore, we assumed that transformations between FA leading to the production of $\mathrm{C} 16: 1 \omega 9$ and C22:6 $\omega 3$ would be a more likely scenario to explain the accumulation of these FA in the liver, rather than the selective uptake.

3.2.7. The bad fitting of C16:1w9 in PPAR $\alpha$ KO mice is likely explained by incomplete oxidation of $C 18: 1 \omega 9$

C16:1 $\omega 9$ can be produced by oxidation from C18:1 $\omega 9$ (Fig. 2). In PPAR $\alpha$ $\mathrm{KO}$ mice, the proportion of $\mathrm{C} 16: 1 \omega 9$ in the liver is very small (1.7\% of total liver FA at $72 \mathrm{~h}$ of fasting), compared with that of $\mathrm{C} 18: 1 \omega 9$ (26\% of total hepatic

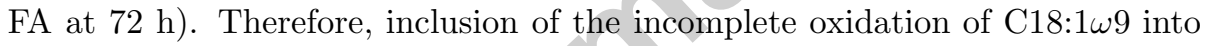
$\mathrm{C} 16: 1 \omega 9$ might fit the latter FA, without reducing the quality of fit for $\mathrm{C} 18: 1 \omega 9$ (this reaction will be included in model 2).

3.2.8. The bad fitting of C22:6w3 in PPAR $\alpha$ KO mice is likely explained by elongation/desaturation of $C 18: 3 \omega 3$

$\mathrm{C} 22: 6 \omega 3$ was underestimated in PPAR $\alpha \mathrm{KO}$ mice and can only be produced by elongation and desaturation (Fig. 2) from C18:3 33 , which was overestimated. Therefore, it seems plausible that the absence of the elongation/desaturation pathway in model 1 is the cause of the observed lacks-of-fit. These reactions will be added in model 3 (section 3.4 ).

3.2.9. Building the next model

Model 2 will include incomplete oxidation of C18:1 $\omega 9$ to C16:1 $\omega 9$ in PPAR $\alpha$ $\mathrm{KO}$ mice, and complete oxidation of all $\mathrm{FA}$ in wild-type mice.

\subsection{Model 2: accumulation and (complete or partial) oxidation of FA by the liver}

This model included both FA uptake (see model 1 in section 3.2) and FA oxidation in the liver of both genotypes. 


\subsubsection{Both PPAR $\alpha$ KO and wild-type mice have an active oxidation during} fasting but with much higher rates in wild-type mice

In PPAR $\alpha$ KO mice, only the partial oxidation of C18:1 $\omega 9$ was considered $\left(b_{C 18: 1 \omega 9}=1\right.$ whereas $b_{i}=0$ for the other FA). This oxidation was considered to be incomplete, and produced C16:1 $\omega 9$, which was modeled as $s_{C 18: 1 \omega 9}=0$. As anticipated, the Disturbance error (DE) of C16:1 $\omega 9$ was greater for model $2(87 \%$, Table 6) than from model 1 (8\%, Table 5).Comparatively, the DE for C18:1 $\omega 9$ did not decrease notably (from 44 to $36 \%$, Tables 5 and 6 ). In wild-type mice, the complete oxidation of all FA was required to obtain a better fit of the model, as shown by the increase of the DE for most of the FA (Tables 5 and 6 ). The estimated rate of oxidation of $\mathrm{C} 18: 1 \omega 9$ in $\operatorname{PPAR} \alpha \mathrm{KO}$ mice was only $1 \%$ of that estimated in wild-type mice during a $72 \mathrm{~h}$ fasting period, confirming that wild-type mice had a much higher hepatic FA oxidation compared to PPAR $\alpha$ KO mice.

Fasting is thought to induce a rise of hepatic lipids sensed by PPAR $\alpha$ that, in turn, stimulates the expression of oxidative genes (Kersten et al., 1999). Studies using PPAR $\alpha \mathrm{KO}$ mice have provided evidence that the absence of functional $\operatorname{PPAR} \alpha$ decreases basal levels of $\beta$-oxidation of $\mathrm{C} 16: 0$ in PPAR $\alpha \mathrm{KO}$ mice, but induces no difference in the metabolism of C24:0 compared with wild-type mice (Aoyama et al., 1998). The hepatic expression of most oxidative genes was not induced by fasting in PPAR $\alpha$ KO mice (Leone et al., 1999). Finally, betahydroxybutyrate (i.e., an important ketone product of liver FA oxidation) in $\operatorname{PPAR} \alpha \mathrm{KO}$ mice is $14 \%$ of that in wild-type mice fasted for $24 \mathrm{~h}$ (Kersten et al., 1999).

Considered together, the introduction of a small oxidation rate for PPAR $\alpha$ $\mathrm{KO}$ mice during fasting is not inconsistent with the literature results indicated above. It should be kept in mind that this option will likely underestimate the oxidation rate, because a model with a higher FA uptake rate and a higher oxidation rate would produce similar results. Furthermore, it is possible that

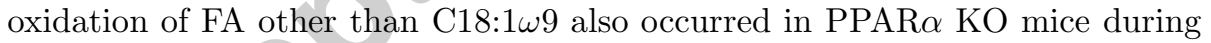
fasting. However, this was not considered because results from model 1 suggested that these oxidation rates are small. Introducing additional oxidation reactions was not necessary to obtain reasonable model predictions (Table 2).

In wild-type mice, the simplest hypothesis of complete oxidation $\left(s_{i}=1\right)$ of FA was sufficient to model the FA content in the liver. Therefore, a step-bystep procedure did not include the use of more refined hypotheses by combining complete and incomplete oxidation. The calculated affinity coefficients for the various FA regarding oxidation are given in Table 3 and the cvMSPE values are in Table 6. The accuracy of the model was generally good, except for C20:5 63 and $\mathrm{C} 22: 6 \omega 3$, which have DE proportions smaller than 25\%. It is known that FA are oxidized in peroxisomes or mitochondria at different rates according to chain length and degree of unsaturation (Mahler et al., 1953; Fritz, 1959; Shindo and Hashimoto, 1978; Mannaerts et al., 1979; Hiltunen et al., 1986). To our knowledge, the relative rates of oxidation of FA are unknown. Even though FA may be oxidized at different rates, the model fitted the experimental data 
well without the need for a time-dependent regulation of oxidation during the fed-to-fasting transition. This suggests that the PPAR $\alpha$-dependent induction of FA oxidation during fasting is either small compared to its constitutive effect, or that it saturates relatively quickly during fasting. The saturation hypothesis may be tested in a specific study focusing on the first 10 to $20 \mathrm{~h}$ of fasting by evaluating the expression of genes and enzymes involved in the oxidation of FA.

\subsubsection{Building the next model}

Model 2 only included FA uptake and oxidation in the liver, but many of the short-comings of model 1 could be resolved by including the oxidation of FA. As discussed for model 1, the poor quality of fit for C22:6 $\omega 3$ cannot be resolved by oxidation and the results for this FA were not better in model 2 than they were in model 1 (Table 6 ). As indicated above, C22:6 $\omega 3$ can only be produced by elongation and desaturation (Fig. 2) from C18:3w3.Thus, to build model 3 we added the elongation and desaturation pathway to model 2 . In wild-type mice, the oxidation rate had to be estimated again to account for the use of $\mathrm{C} 18: 3 \omega 3$ by both oxidation and elongation and desaturation.

\subsection{Model 3: accumulation, oxidation, and desaturation and elongation of FA} by the liver

Essential FA metabolism involves the desaturation and elongation to syn-

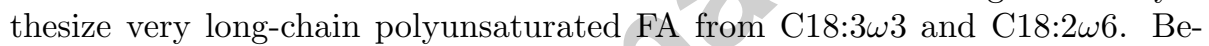
cause delta- 6 desaturase (D6D) is common to $\omega 3$ and $\omega 6$ desaturation pathways, $\mathrm{C} 18: 2 \omega 6$ and $\mathrm{C} 18: 3 \omega 3$ are in competition for this rate-limiting enzyme (Fig. 2).

\subsubsection{Elongation and desaturation process is active during fasting in both geno- types}

For both genotypes model 3 (FA uptake, oxidation and elongation/desaturation) fitted the observed accumulation of C22:6 $\omega 3$ better (Table 7) than model 2 (Table 6). This suggests that elongation and desaturation of C18:3 $\omega 3$ to $\mathrm{C} 22: 6 \omega 3$ are active in both genotypes during fasting. The need to include an active elongation and desaturation pathway in the liver of mice under fasting conditions in PPAR $\alpha \mathrm{KO}$ mice is surprising.

The rate of desaturation and elongation is generally considered to be limited by D6D (Cho et al., 1999), which is transcriptionally-activated by SREBP1 (Matsuzaka et al., 2002). The nuclear form of SREBP-1 in the liver of mice has a very low, barely detectable level after $6 \mathrm{~h}$ of fasting (Horton et al., 1998). A second transcriptional activator of D6D is PPAR $\alpha$ (Matsuzaka et al., 2002). Considering that PPAR $\alpha$ was invalidated in $\mathrm{PPAR} \alpha \mathrm{KO}$ mice, and that SREBP1 is inhibited by fasting (Horton et al., 1998), transcription and activity of D6D should have rapidly decreased during the first hours of fasting in PPAR $\alpha \mathrm{KO}$ livers. 


\subsubsection{Experimental validation: $m R N A$ expression of D6D is stable during the} first 24 h of fasting

To support at least in part the results of our model, mRNA levels of D6D were monitored by real-time quantitative PCR in the liver of mice after $0,24,48$, and $72 \mathrm{~h}$ of fasting. As shown in Fig. 4, D6D mRNA levels remained constant during the first $24 \mathrm{~h}$ of fasting in the two genotypes.

D6D mRNA levels significantly decreased at $72 \mathrm{~h}$ and $48 \mathrm{~h}$ in wild-type and $\operatorname{PPAR} \alpha \mathrm{KO}$ livers respectively. Therefore, D6D expression seems to be regulated in a time-dependent manner during fasting and its regulation partially depends on PPAR $\alpha$ expression only after 24h. This result is consistent with the need to incorporate the desaturation/elongation pathway in our model for both genotypes to correctly fit the FA data. Additionally, these data suggest that the mechanisms by which D6D mRNA expression is regulated during fasting involve other molecular players than the known major regulators PPAR $\alpha$ and SREBP1. These unknown regulators remain to be identified but could respond to several hormonal or metabolic signals that are modulated during fasting, possibly differentially between wild-type and $\operatorname{PPAR} \alpha \mathrm{KO}$ mice. Several hormones have been shown to reduce D6D expression or activity in the liver (for a review see (Brenner, 2003)) including glucagon and glucocorticoids which are increased during fasting. However, to our knowledge, the accurate kinetics of these hormonal changes have not yet been described in wild-type and PPAR $\alpha$ knockout mice. Hence, it is difficult to predict whether such hormonal signal may differentially influence D6D expression between these two genotypes. On the other hand, several metabolic parameters differ between fasted wild-type and PPAR $\alpha$ KO mice. For instance, the latter exhibit hypoglycemia and reduced metabolic rates during fasting (Kersten et al., 1999) in addition to impaired FA oxidation (Le May et al., 2000). In the liver, glucose and FA (Guillou et al., 2008) may influence the transcription of enzymes involved in FA metabolism. Changes in glucose, FA or other metabolites that may influence the differential expression of $\mathrm{D} 6 \mathrm{D}$ reported here remains to be investigated.

\section{Conclusion}

A simple model including fatty acids uptake, oxidation and elongation/desaturation was able to predict correctly the variation of most fatty acids in the liver of both PPAR $\alpha \mathrm{KO}$ and wild-type mice. This model included parameter estimates in adipose tissue and liver to explain the change in fatty acid content in the liver during fasting.

Experimental measurements in different organs obtained in the same animals and under the same experimental conditions are strongly needed in the future to predict the dynamics of fatty acids in a given organ. The presence of a basal oxidation in both $\operatorname{PPAR} \alpha \mathrm{KO}$ and wild-type mice with a rate that depended on the genotype but not on the time of fasting shows that PPAR $\alpha$ has a constitutional effect on oxidation but little or no time-dependent effects.

The presence of an active elongation and desaturation in both genotypes was surprising in the liver of fasting mice. It confirms and strengthens earlier results 
(Nakamura and Nara, 2003) suggesting that the unsaturated fatty acids content in tissues is maintained within physiological ranges by feedback regulation of synthetic pathways.

The regulation of desaturases by $\operatorname{PPAR} \alpha$ is different from the main role of PPAR $\alpha$ in inducing oxidation (Nakamura and Nara, 2003) and cannot be explained by the differential behavior of various desaturases such as delta-6desaturase and stearoyl-coenzyme A desaturase (Radulescu et al., 2006). Our results suggest that mechanisms other than $\operatorname{PPAR} \alpha$ activation are likely to contribute to the regulation of delta-6-desaturase activity during fasting.

In the future, the model could be used to design specific experiments aiming at a better understanding of lipid metabolism as regulated by the nutritional status. The same set of equations could be used in other tissues such as muscle, in other animal species, to predict inter-species variability in lipid metabolism or in animals fed diets with different FA compositions. 


\section{References}

Aoyama, T., Peters, J., Iritani, N., Nakajima, T., Furihata, K., Hashimoto, T., Gonzalez, F., 1998. Altered Constitutive Expression of Fatty Acid-metabolizing Enzymes in Mice Lacking the Peroxisome Proliferator-activated Receptor $\alpha(\operatorname{PPAR} \alpha)$. Journal of Biological Chemistry 273 (10), 5678-5684.

Berk, P., Stump, D., 1999. Mechanisms of cellular uptake of long chain free fatty acids. Molecular and Cellular Biochemistry 192 (1), 17-31.

Bibby, J., 1977. Predictions and improved estimation in linear models. J. Wiley \& Sons, Chichester.

Bookout, A., Jeong, Y., Downes, M., Yu, R., Evans, R., Mangelsdorf, D., 2006. Anatomical profiling of nuclear receptor expression reveals a hierarchical transcriptional network. Cell 126 (4), 789-99.

Brenner, R., 2003. Hormonal modulation of delta6 and delta5 desaturases: case of diabetes. Prostaglandins Leukot Essent Fatty Acids 68 (2), 151-62.

Calvetti, D., Kuceyeski, A., Somersalo, E., 2008. A mathematical model of liver metabolism: from steady state to dynamic. In: Journal of Physics: Conference Series. Vol. 124 (1). Institute of Physics Publishing, p. 012012.

Campbell, P., Carlson, M., Hill, J., Nurjhan, N., 1992. Regulation of free fatty acid metabolism by insulin in humans: role of lipolysis and reesterification. American Journal of PhysiologyEndocrinology And Metabolism 263 (6), 1063-1069.

Cao, H., Gerhold, K., Mayers, J., Wiest, M., Watkins, S., Hotamisligil, G., 2008. Identification of a Lipokine, a Lipid Hormone Linking Adipose Tissue to Systemic Metabolism. Cell 134 (6), 933-944.

Chalhoub, E., Hanson, R., Belovich, J., 2007a. A Computer Model of Gluconeogenesis and Lipid Metabolism in the Perfused Liver. American Journal of Physiology- Endocrinology And Metabolism, 00161-2007.

Chalhoub, E., Xie, L., Balasubramanian, V., Kim, J., Belovich, J., 2007b. A Distributed Model of Carbohydrate Transport and Metabolism in the Liver during Rest and High-Intensity Exercise. Annals of Biomedical Engineering 35 (3), 474-491.

Cho, H., Nakamura, M., Clarke, S., 1999. Cloning, expression, and nutritional regulation of the mammalian $\Delta-6$ desaturase. Journal of Biological Chemistry 274 (1), 471-477.

Costet, P., Legendre, C., More, J., Edgar, A., Galtier, P., Pineau, T., 1998. Peroxisome Proliferator-activated Receptor $\alpha$-Isoform Deficiency Leads to Progressive Dyslipidemia with Sexually Dimorphic Obesity and Steatosis. Journal of Biological Chemistry 273 (45), 29577-29585.

Desvergne, B., Wahli, W., 1999. Peroxisome Proliferator-Activated Receptors: Nuclear Control of Metabolism 1. Endocrine Reviews 20 (5), 649-688.

Duplus, E., Glorian, M., Forest, C., 2000. Fatty Acid Regulation of Gene Transcription. Journal of Biological Chemistry 275 (40), 30749-30752.

Fattal, D., Ben-Shaul, A., 1993. A molecular model for lipid-protein interaction in membranes: the role of hydrophobic mismatch. Biophysical Journal 65 (5), 1795-1809.

Forns, X., Ampurdanes, S., Llovet, J., Aponte, J., Quinto, L., Martinez-Bauer, E., Bruguera, M., Sanchez-Tapias, J., Rodes, J., 2002. Identification of chronic hepatitis C patients without hepatic fibrosis by a simple predictive model. Hepatology 36 (4), 986-992. 
Fritz, I., 1959. Action of carnitine on long chain fatty acid oxidation by liver. American Journal of Physiology 197 (2), 297-304.

Guillou, H., Martin, P., Jan, S., D'Andrea, S., Roulet, A., Catheline, D., Rioux, V., Pineau, T., Legrand, P., 2002. Comparative effect of fenofibrate on hepatic desaturases in wild-type and peroxisome proliferator-activated receptor alpha-deficient mice. Lipids 37 (10), 981-9.

Guillou, H., Martin, P., Pineau, T., 2008. Transcriptional regulation of hepatic fatty acid metabolism. Subcell Biochem. 49, 3-47.

Hashimoto, T., Cook, W., Qi, C., Yeldandi, A., Reddy, J., Rao, M., 2000. Defect in peroxisome proliferator-activated receptor $\alpha$-inducible fatty acid oxidation determines the severity of hepatic steatosis in response to fasting. Journal of Biological Chemistry 275 (37), 2891828928.

Hiltunen, J., Karki, T., Hassinen, I., Osmundsen, H., 1986. Beta Oxidation of Polyunsaturated Fatty Acids by Rat Liver Peroxisomes A role for 2,4-dienoyl-coenzyme A redyctase in peroxisomal beta-oxidation. Journal of Biological Chemistry 261 (35), 16484-16493.

Horton, J., Bashmakov, Y., Shimomura, I., Shimano, H., 1998. Regulation of sterol regulatory element binding proteins in livers of fasted and refed mice. Proceedings of the National Academy of Sciences 95 (11), 5987-5992.

Horton, J., Goldstein, J., Brown, M., 2002. SREBPs: activators of the complete program of cholesterol and fatty acid synthesis in the liver. Journal of Clinical Investigation 109 (9), 1125 .

Jakobsson, A., Westerberg, R., Jacobsson, A., 2006. Fatty acid elongases in mammals: Their regulation and roles in metabolism. Progress in Lipid Research 45 (3), 237-249.

Kanehisa, M., Araki, M., Goto, S., Hattori, M., Hirakawa, M., Itoh, M., Katayama, T., Kawashima, S., Okuda, S., Tokimatsu, T., Yamanishi, Y., 2008. KEGG for linking genomes to life and the environment. Nucleic Acids Res. 36, D480-D484.

Kersten, S., Seydoux, J., Peters, J., Gonzalez, F., Desvergne, B., Wahli, W., 1999. Peroxisome proliferator-activated receptor $\alpha$ mediates the adaptive response to fasting. Journal of Clinical Investigation 103 (11), 1489.

Kim, J., Sarraf, P., Wright, M., Yao, K., Mueller, E., Solanes, G., Lowell, B., Spiegelman, B., 1998. Nutritional and insulin regulation of fatty acid synthetase and leptin gene expression through ADD1/SREBP1. Journal of Clinical Investigation 101 (1), 1.

Knauf, C., Rieusset, J., Foretz, M., Cani, P., Uldry, M., Hosokawa, M., Martinez, E., Bringart, M., Waget, A., Kersten, S., Desvergne, B., Gremlich, S., Wahli, W., Seydoux, J., Delzenne, N., Thorens, B., Burcelin, R., 2006. Peroxisome proliferator-activated receptor-alpha-null mice have increased white adipose tissue glucose utilization, glut4, and fat mass: Role in liver and brain. Endocrinology 147 (9), 4067-78.

Le May, C., Pineau, T., Bigot, K., Kohl, C., Girard, J., Pégorier, J., 2000. Reduced hepatic fatty acid oxidation in fasting pparalpha null mice is due to impaired mitochondrial hydroxymethylglutaryl-coa synthase gene expression. FEBS Lett. 475 (3), 163-6.

Lee, S., Chan, W., Lo, C., Wan, D., Tsang, D., Cheung, W., 2004. Requirement of PPARalpha in maintaining phospholipid and triglyceride homeostasis during energy deprivation. The Journal of Lipid Research, M400078.

Lee, S., Pineau, T., Drago, J., Lee, E., Owens, J., Kroetz, D., Fernandez-Salguero, P., Westphal, H., Gonzalez, F., 1995. Targeted disruption of the alpha isoform of the peroxisome proliferator-activated receptor gene in mice results in abolishment of the pleiotropic effects of peroxisome proliferators. Molecular and Cellular Biology 15 (6), 3012-3022. 
Leone, T., Weinheimer, C., Kelly, D., 1999. A critical role for the peroxisome proliferatoractivated receptor $\alpha(\operatorname{PPAR} \alpha)$ in the cellular fasting response: The PPAR $\alpha$-null mouse as a model of fatty acid oxidation disorders. Proceedings of the National Academy of Sciences 96 (13), 7473-7478.

Mahler, H., Wakil, S., Bock, R., 1953. Studies on fatty acid oxidation I. Enzymtic activation of fatty acids. Journal of Biological Chemistry 204 (1), 453-468.

Mannaerts, G., Debeer, L., Thomas, J., De Schepper, P., 1979. Mitochondrial and peroxisomal fatty acid oxidation in liver homogenates and isolated hepatocytes from control and clofibrate-treated rats. Journal of Biological Chemistry 254 (11), 4585-4595.

Martin, P., Guillou, H., Lasserre, F., Dï $\frac{1}{2}$ jean, S., Lan, A., Pascussi, J., Sancristobal, M., Legrand, P., Besse, P., Pineau, T., 2007. Novel aspects of PPARalpha-mediated regulation of lipid and xenobiotic metabolism revealed through a nutrigenomic study. Hepatology 45 (3), 767-77.

Matsuzaka, T., Shimano, H., Yahagi, N., Amemiya-Kudo, M., Yoshikawa, T., Hasty, A., Tamura, Y., Osuga, J., Okazaki, H., Iizuka, Y., et al., 2002. Dual regulation of mouse $\Delta 5$-and $\Delta 6$-desaturase gene expression by SREBP-1 and PPAR $\alpha$. The Journal of Lipid Research 43 (1), 107-114.

Mazzucotelli, A., Viguerie, N., Tiraby, C., Annicotte, J., Mairal, A., Klimcakova, E., Lepin, E., Delmar, P., Dejean, S., Tavernier, G., Lefort, C., Hidalgo, J., Pineau, T., Fajas, L., Clément, K., Langin, D., 2007. The transcriptional coactivator peroxisome proliferator activated receptor (ppar)gamma coactivator-1 alpha and the nuclear receptor ppar alpha control the expression of glycerol kinase and metabolism genes independently of ppar gamma activation in human white adipocytes. Diabetes 56 (10), 2467-75

Muiruri, K., Leveille, G., 1970. In vitro fatty acid synthesis and enzyme activity in liver and adipose tissue of the mouse. International Journal of Biochemistry 1, 254-256.

Murray, R., Granner, D., Rodwell, V., 2006. Harper's Illustrated Biochemistry, 27th Edition. The McGraw-Hill Companies.

Nakamura, M., Nara, T., 2003. Essential fatty acid synthesis and its regulation in mammals. Prostaglandins, Leukotrienes \& Essential Fatty Acids 68 (2), 145-150.

Nelder, J., Mead, R., 1965. A Simplex Method for Function Minimization. The Computer Journal 7 (4), 308.

Oikari, S., Ahtialansaari, T., Huotari, A., Kiehne, K., Folsch, U., Wolffram, S., Janne, J., Alhonen, L., Herzig, K., 2008. Effect of medium and long chain fatty acid diet on PPARs and SREBP-1 expression and glucose homeostasis in ACBP overexpressing transgenic rats. Acta Physiologica.

Peirson, S., Butler, J., Foster, R., 2003. Experimental validation of novel and conventional approaches to quantitative real-time PCR data analysis. Nucleic Acids Research 31 (14), e73.

Radulescu, O., Lagarrigue, S., Siegel, A., Veber, P., Le Borgne, M., 2006. Topology and static response of interaction networks in molecular biology. Journal of the Royal Society Interface 3 (6), 185-196.

Remesy, C., Demigne, C., 1983. Changes in availability of glucogenic and ketogenic substrates and liver metabolism in fed or starved rats. Ann Nutr Metab 27 (1), 57-70.

Seidelin, K., 1995. Fatty acid composition of adipose tissue in humans. Implications for the dietary fat-serum cholesterol-CHD issue. Progress in Lipid Research 34 (3), 199-217. 
Sessler, A., Ntambi, J., 1998. Polyunsaturated Fatty Acid Regulation of Gene Expression. Journal of Nutrition 128 (6), 923-926.

Shimano, H., Yahagi, N., Amemiya-Kudo, M., Hasty, A., Osuga, J., Tamura, Y., Shionoiri, F., Iizuka, Y., Ohashi, K., Harada, K., et al., 1999. Sterol Regulatory Element-binding Protein-1 as a Key Transcription Factor for Nutritional Induction of Lipogenic Enzyme Genes. Journal of Biological Chemistry 274 (50), 35832-35839.

Shindo, Y., Hashimoto, T., 1978. Acyl-Coenzyme A Synthetase and Fatty Acid Oxidation in Rat Liver Peroxisomes. Journal of Biochemistry 84 (5), 1177.

Shirai, K., 2004. Obesity as the core of the metabolic syndrome and the management of coronary heart disease. Current Medical Research and Opinion 20 (3), 295-304.

Simopoulos, A., 1991. Omega-3 fatty acids in health and disease and in growth and development (see comments). Am. J. Clin. Nutr 54, 438.

Sokolović, M., Sokolović, A., Wehkamp, D., van Themaat, E., de Waart, D., Gilhuijs-Pederson, L., Nikolsky, Y., van Kampen, A., Hakvoort, T., Lamers, W., 2008. The transcriptomic signature of fasting murine liver. BMC Genomics 9, 528 .

Sorrentino, D., Berk, P., 1993. Free fatty acids and the sinusoidal plasma membrane: Concepts, trends and controversies. In Hepatic transport and bile secretion: physiology and pathophysiology. N Tavoloni and PD Berk (eds). Raven Press,New York (USA).

Tedeschi, L., 2006. Assessment of the adequacy of mathematical models. Agricultural Systems $89(2-3), 225-247$.

Uauy, R., Mena, P., Rojas, C., 2007. Essential fatty acids in early life: structural and functional role. Proceedings of the Nutrition Society 59 (01), 3-15.

Unger, R., Zhou, Y., Orci, L., 1999. Regulation of fatty acid homeostasis in cells: Novel role of leptin. Proceedings of the National Academy of Sciences 96 (5), 2327-2332.

van Milgen, J., 2002. Modeling Biochemical Aspects of Energy Metabolism in Mammals 1. Journal of Nutrition 132 (10), 3195-3202.

Wang, Y., Botolin, D., Xu, J., Christian, B., Mitchell, E., Jayaprakasam, B., Nair, M., Peters, J., Busik, J., Olson, L., et al., 2006. Regulation of hepatic fatty acid elongase and desaturase expression in diabetes and obesity. The Journal of Lipid Research 47 (9), 2028. 
Table 1: Summary of models obtained with the step-by-step procedure. The models predict variations in hepatic fatty acid (FA) composition during fasting.

\begin{tabular}{|c|c|}
\hline (2) & Differential equations \\
\hline$\forall i \in\{$ all $F A\}$ & $\frac{d X_{i}^{L}}{d t}=\Phi_{i}^{i n}$ \\
\hline Model 2 & Differential equations \\
\hline $\begin{array}{l}\forall i \in\{C 14: 0, C 16: 0, C 16: 1 w 7, C 18: 0, C 18: 1 \omega 7, \\
C 18: 3 \omega 3, C 18: 2 \omega 6, C 20: 5 \omega 3, C 22: 6 \omega 3, C 20: 3 \omega 6, \\
C 20: 4 \omega 6\}\end{array}$ & $\begin{array}{l}\frac{d X_{i}^{L}}{d t}=\Phi_{i}^{i n}-\Phi_{i}^{O x i} \\
\text { with } s_{i}=1\end{array}$ \\
\hline$i=C 18: 1 \omega 9$ & $\begin{array}{l}\frac{d X_{i}^{L}}{d t}=\Phi_{i}^{i n}-\Phi_{i}^{O x i} \\
\text { with } s_{i}=0 \text { in PPAR } \alpha \mathrm{KO} \text { mice } \\
\text { and } s_{i}=1 \text { in wild-type mice }\end{array}$ \\
\hline$i=C 16: 1 \omega 9$ & $\begin{array}{l}\frac{d X_{i}^{L}}{d t}=\Phi_{i}^{i n}-\Phi_{i}^{O x i}+\Phi_{C 18: 1 \omega 9}^{\text {IncompleteOxi }} \\
\text { with } s_{i}=1\end{array}$ \\
\hline Model 3 & Differential equations \\
\hline$\forall i \in\{C 14: 0, C 16: 0, C 16: 1 w 7, C 18: 0, C 18: 1 \omega 7\}$ & $\begin{array}{l}\frac{d X_{i}^{L}}{d t}=\Phi_{i}^{i n}-\Phi_{i}^{O x i} \\
\text { with } s_{i}=1\end{array}$ \\
\hline$\forall i \in\{C 18: 3 \omega 3, C 18: 2 \omega 6\}$ & $\begin{array}{l}\frac{d X_{i}^{L}}{d t}=\Phi_{i}^{i n}-\Phi_{i}^{O x i}-\Phi_{i}^{\text {Desat }} \\
\text { with } s_{i}=1\end{array}$ \\
\hline$\forall i \in\{S \omega 3, S \omega 6\}$ & $\begin{array}{l}\frac{d X_{i}^{L}}{d t}=\Phi_{i}^{i n}-\Phi_{i}^{O x i}+\Phi_{i}^{\text {Desat }} \\
\text { with } s_{i}=1\end{array}$ \\
\hline$i=C 18: 1 \omega 9$ & $\begin{array}{l}\frac{d X_{i}^{L}}{d t}=\Phi_{i}^{i n}-\Phi_{i}^{O x i} \\
\text { with } s_{i}=0 \text { in PPAR } \alpha \text { KO mice } \\
\text { and } s_{i}=1 \text { in wild-type mice }\end{array}$ \\
\hline$i=C 16: 1 \omega 9$ & $\begin{array}{l}\frac{d X_{i}^{L}}{d t}=\Phi_{i}^{i n}-\Phi_{i}^{O x i}+\Phi_{C 18: 1 \omega 9}^{\text {IncompleteOxi }} \\
\text { with } s_{i}=1\end{array}$ \\
\hline
\end{tabular}


Table 2: Fatty acid contents ( $\mu$ moles) in the liver of wild type or PPAR $\alpha$ knockout mice during fasting

\begin{tabular}{|c|c|c|c|c|c|c|c|c|}
\hline \multirow{2}{*}{$\begin{array}{l}\text { Genotype } \\
\text { Fasting time }(\mathrm{h})\end{array}$} & \multicolumn{4}{|c|}{ PPAR $\alpha$ knockout } & \multicolumn{4}{|c|}{ Wild type } \\
\hline & 0 & 72 & $72 \mathrm{~h} / 0 \mathrm{~h}^{a}$ & $\mathrm{P}$ value ${ }^{b}$ & 0 & 72 & $72 \mathrm{~h} / 0 \mathrm{~h}$ & $\mathrm{P}$ value ${ }^{a}$ \\
\hline Fatty acid & & & & & & & & \\
\hline C14:0 & 0.43 & 10.17 & 23.45 & $<0.001$ & 0.26 & 3.07 & 11.81 & $<0.001$ \\
\hline C16:0 & 31.77 & 129.76 & 4.08 & $<0.001$ & 23.26 & 53.49 & 2.30 & $<0.001$ \\
\hline $\mathrm{C} 16: 1 \omega 9$ & 0.51 & 16.53 & 32.41 & $<0.001$ & 0.38 & 5.31 & 13.97 & $<0.001$ \\
\hline $\mathrm{C} 16: 1 \omega 7$ & 1.34 & 21.06 & 15.72 & $<0.001$ & 1.91 & 6.73 & 3.52 & 0.001 \\
\hline C18:0 & 15.79 & 34.54 & 2.19 & $<0.001$ & 8.69 & 15.92 & 1.83 & $<0.001$ \\
\hline $\mathrm{C} 18: 1 \omega 9$ & 14.09 & 257.35 & 18.26 & $<0.001$ & 11.99 & 85.43 & 7.13 & $<0.001$ \\
\hline $\mathrm{C} 18: 1 \omega 7$ & 1.74 & 19.12 & 10.99 & $<0.001$ & 1.94 & 6.24 & 3.22 & $<0.001$ \\
\hline $\mathrm{C} 18: 2 \omega 6$ & 38.57 & 455.88 & 11.81 & $<0.001$ & 15.11 & 114.84 & 7.60 & $<0.001$ \\
\hline $\mathrm{C} 18: 3 \omega 3$ & 1.21 & 9.99 & 8.26 & $<0.001$ & 0.41 & 2.50 & 6.10 & $<0.001$ \\
\hline $\mathrm{C} 20: 1 \omega 9$ & 0.61 & 6.17 & 10.11 & $<0.001$ & 0.29 & 2.87 & 9.90 & $<0.001$ \\
\hline $\mathrm{C} 20: 3 \omega 6$ & 1.06 & 1.99 & 1.88 & 0.017 & 1.22 & 1.04 & 0.85 & 0.037 \\
\hline $\mathrm{C} 20: 4 \omega 6$ & 12.45 & 15.54 & 1.25 & 0.825 & 9.16 & 10.81 & 1.18 & 0.196 \\
\hline $\mathrm{C} 20: 5 \omega 3$ & 0.26 & 0.36 & 1.38 & 0.115 & 0.20 & 0.97 & 4.85 & $<0.001$ \\
\hline $\mathrm{C} 22: 6 \omega 3$ & 6.30 & 10.97 & 1.74 & 0.021 & 4.09 & 14.31 & 3.50 & $<0.001$ \\
\hline
\end{tabular}

${ }^{a}$ Ratios between the $72 \mathrm{~h}$ and $0 \mathrm{~h}$ of fasting are presented although these ratios may be largely influenced by some very low concentrations observed under the fed condition $(\mathrm{t}=0 \mathrm{~h})$.

${ }^{b} \mathrm{P}$ value associated to the slope of the linear regression :Fatty acid quantity $=$ slope $\times$ time + intercept in each genotype. This value was considered to be significant for $\mathrm{P}$ value $<0.05$.

Table 3: Calculated parameters of the different models built to depict fatty acid composition in the liver of wild-type or PPAR $\alpha$ knockout mice during fasting

\begin{tabular}{|c|c|c|c|c|c|c|}
\hline \multirow{2}{*}{$\begin{array}{l}\text { Genotype } \\
\text { Parameters }\end{array}$} & \multicolumn{3}{|c|}{ PPAR $\alpha$ knockout mice } & \multicolumn{3}{|c|}{ Wild type mice } \\
\hline & Model1 & Model2 & Model3 & Model1 & Model2 & Model3 \\
\hline$K_{i n}$ & $2.9 \mathrm{e}+00$ & $2.9 \mathrm{e}+00$ & $2.9 \mathrm{e}+00$ & $2.9 \mathrm{e}+00$ & $2.9 \mathrm{e}+00$ & $2.9 \mathrm{e}+00$ \\
\hline$K_{o x i}(m m o l . h$ & 0 & $1.05 \mathrm{e}-04$ & $1.05 \mathrm{e}-04$ & 0 & $9.92 \mathrm{e}-03$ & $9.92 \mathrm{e}-03$ \\
\hline$s_{i}(i \neq C 18: 1 \omega 9)$ & 1 & 1 & 1 & 1 & 1 & \\
\hline$s_{C 18: 1 \omega 9}$ & 0 & 0 & 0 & 1 & 1 & 1 \\
\hline${ }^{b} C 14: 0$ & 0 & 0 & 0 & $1.43 \mathrm{e}-01$ & $1.43 \mathrm{e}-01$ & $1.43 \mathrm{e}-01$ \\
\hline${ }^{b} C 16: 0$ & 0 & 0 & 0 & $6.96 \mathrm{e}-02$ & $6.96 \mathrm{e}-02$ & $6.96 \mathrm{e}-02$ \\
\hline${ }^{s} C 16: 1 \omega 9$ & 0 & 0 & 0 & $2.51 \mathrm{e}-02$ & $2.51 \mathrm{e}-02$ & $2.51 \mathrm{e}-02$ \\
\hline${ }^{s} C 16: 1 \omega 7$ & 0 & 0 & 0 & $2.22 \mathrm{e}-01$ & $2.22 \mathrm{e}-01$ & $2.22 \mathrm{e}-01$ \\
\hline${ }^{s} C 18: 0$ & 0 & 0 & 0 & $1.67 \mathrm{e}-02$ & $1.67 \mathrm{e}-02$ & $1.67 \mathrm{e}-02$ \\
\hline$s_{C 18: 1 \omega 9}$ & 1 & 1 & 1 & $9.51 \mathrm{e}-02$ & $9.51 \mathrm{e}-02$ & $9.51 \mathrm{e}-02$ \\
\hline${ }^{s} C 18: 1 \omega 7$ & 0 & 0 & 0 & $1.03 \mathrm{e}-01$ & $1.03 \mathrm{e}-01$ & $1.03 \mathrm{e}-01$ \\
\hline${ }^{s} C 18: 2 \omega 6$ & 0 & 0 & 0 & $6.39 \mathrm{e}-02$ & $6.39 \mathrm{e}-02$ & $6.39 \mathrm{e}-02$ \\
\hline$s_{C 18: 3 \omega 3}$ & 0 & 0 & 0 & $1.54 \mathrm{e}-01$ & $1.54 \mathrm{e}-01$ & $1.54 \mathrm{e}-01$ \\
\hline$s_{C 20: 1 \omega 9}$ & 0 & 0 & 0 & $7.18 \mathrm{e}-02$ & $7.18 \mathrm{e}-02$ & $7.18 \mathrm{e}-02$ \\
\hline${ }^{s} C 20: 3 \omega 6$ & 0 & 0 & 0 & $3.44 \mathrm{e}-02$ & $3.44 \mathrm{e}-02$ & $3.44 \mathrm{e}-02$ \\
\hline${ }^{s} C 20: 4 \omega 6$ & 0 & 0 & 0 & $8.58 \mathrm{e}-04$ & $8.58 \mathrm{e}-04$ & $8.58 \mathrm{e}-04$ \\
\hline$s_{C 20: 5 \omega 3}$ & 0 & 0 & 0 & 0 & 0 & 0 \\
\hline${ }^{s} C 22: 6 \omega 3$ & 0 & 0 & 0 & 0 & 0 & 0 \\
\hline$s_{C 22: 6 \omega 3}$ & 0 & 0 & 0 & 0 & 0 & 0 \\
\hline$K_{\text {desat }}\left(m o l . h^{-1}\right)$ & 0 & 0 & $4.92 \mathrm{e}-05$ & 0 & 0 & $9.2 \mathrm{e}-05$ \\
\hline$d_{C 18: 3 \omega 3}$ & 1 & 1 & 1 & 0.99956 & 0.99956 & 0.99956 \\
\hline$d_{C 18: 2 \omega 6}$ & 0 & 0 & 0 & 0.00044 & 0.00044 & 0.00044 \\
\hline
\end{tabular}


Table 4: Estimates of linear regressions for fatty acid contents during a 72 hours of fast in adipose tissue of wild type or PPAR $\alpha$ knockout mice

\begin{tabular}{|c|c|c|c|c|c|c|}
\hline \multirow[t]{2}{*}{ Genotype } & \multicolumn{3}{|c|}{ PPAR $\alpha$ knockout } & \multicolumn{3}{|c|}{ Wild-type } \\
\hline & $\begin{array}{l}\text { Intercept } \\
(\mu \text { moles })\end{array}$ & $\begin{array}{l}\text { Slope } \\
\left(\text { nmol. } h^{-1}\right)\end{array}$ & $R^{a}$ & $\begin{array}{l}\text { Intercept } \\
(\mu \text { moles })\end{array}$ & $\begin{array}{l}\text { Slope } \\
(\text { nmol.h }-1)\end{array}$ & $R$ \\
\hline Fatty acids & & & & & & \\
\hline C14:0 & 3.91 & -42.68 & -0.81 & 4.64 & -59.58 & -0.98 \\
\hline C16:0 & 57.22 & -623.63 & -0.88 & 71.28 & -962.29 & -0.99 \\
\hline $\mathrm{C} 16: 1 \omega 9$ & 2.34 & -23.38 & -0.87 & 2.63 & -31.80 & -0.98 \\
\hline C16:1 $1 \omega 7$ & 15.50 & -183.58 & -0.87 & 21.13 & -311.27 & -0.96 \\
\hline C18:0 & 5.76 & -53.23 & -0.85 & 6.49 & -75.27 & -0.99 \\
\hline $\mathrm{C} 18: 1 \omega 9$ & 87.23 & -903.41 & -0.87 & 105.20 & -1352.02 & -0.99 \\
\hline C $18: 1 \omega 7$ & 6.57 & -67.63 & -0.86 & 8.72 & -113.66 & -0.98 \\
\hline $\mathrm{C} 18: 2 \omega 6$ & 137.19 & -1448.85 & -0.87 & 114.91 & -1485.97 & -1.00 \\
\hline $\mathrm{C} 18: 3 \omega 3$ & 6.17 & -72.85 & -0.90 & 5.83 & -83.98 & -0.98 \\
\hline $\mathrm{C} 20: 1 \omega 9$ & 1.70 & -14.58 & -0.81 & 2.85 & -28.57 & -0.95 \\
\hline $\mathrm{C} 20: 3 \omega 6$ & 0.27 & -2.37 & -0.80 & 0.58 & -6.74 & -0.96 \\
\hline 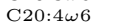 & 0.44 & -4.00 & -0.86 & 0.89 & -11.36 & -0.95 \\
\hline $\mathrm{C} 20: 5 \omega 3$ & 0.14 & -1.14 & -0.69 & 0.33 & -3.61 & -0.94 \\
\hline $\mathrm{C} 22: 6 \omega 3$ & 0.14 & -0.76 & -0.47 & 0.66 & -7.51 & -0.94 \\
\hline Average & 23.18 & -245.86 & -0.81 & 24.72 & -323.83 & -0.97 \\
\hline
\end{tabular}

${ }^{a}$ Pearson correlation coefficient.

Table 5: MSPE coefficient of variation and its decomposition in the model 1 predicting fatty acid composition in the liver of wild type or PPAR $\alpha$ knock out mice during fasting. This model included only fatty acid uptake from adipose tissue.

\begin{tabular}{|c|c|c|c|c|c|c|c|c|}
\hline $\begin{array}{l}\text { Genotype } \\
\text { Statistics }\end{array}$ & cvMSPE $^{\mathrm{F}}$ & $\begin{array}{l}\overline{\mathrm{AR} \alpha \mathrm{knc}} \\
\mathrm{CE}(\%)\end{array}$ & $\begin{array}{l}\text { out mic } \\
\operatorname{RE}(\%)\end{array}$ & $\mathrm{DE}(\%)$ & cvMSPE & $\begin{array}{l}\text { Wild ty } \\
\text { CE(\%) }\end{array}$ & $\begin{array}{l}\text { mice } \\
\text { RE(\%) }\end{array}$ & $\mathrm{DE}(\%)$ \\
\hline C14:0 & $2.77 \mathrm{e}-01$ & 0 & 24 & 76 & $4.42 \mathrm{e}+00$ & 55 & 44 & 0 \\
\hline C16:0 & $3.16 \mathrm{e}-01$ & 6 & 57 & 37 & $2.15 \mathrm{e}+00$ & 52 & 48 & 1 \\
\hline $\mathrm{C} 16: 1 \omega 9$ & $8.29 \mathrm{e}-01$ & 43 & 49 & 8 & $8.23 \mathrm{e}-01$ & 59 & 30 & 11 \\
\hline $\mathrm{C} 16: 1 \omega 7$ & $7.73 \mathrm{e}-01$ & 12 & 60 & 28 & $6.89 \mathrm{e}+00$ & 53 & 47 & 0 \\
\hline C18:0 & $1.35 \mathrm{e}-01$ & 34 & 5 & 60 & $5.28 \mathrm{e}-01$ & 62 & 35 & 3 \\
\hline $\mathrm{C} 18: 1 \omega 9$ & $2.59 \mathrm{e}-01$ & 49 & 7 & 44 & $2.94 \mathrm{e}+00$ & 54 & 45 & 1 \\
\hline $\mathrm{C} 18: 1 \omega 7$ & $2.22 \mathrm{e}-01$ & 43 & 4 & 53 & $3.19 \mathrm{e}+00$ & 56 & 44 & 0 \\
\hline $\mathrm{C} 18: 2 \omega 6$ & $2.91 \mathrm{e}-01$ & 55 & 7 & 38 & $1.98 \mathrm{e}+00$ & 51 & 48 & 1 \\
\hline $\mathrm{C} 18: 3 \omega 3$ & $6.62 \mathrm{e}-01$ & 13 & 67 & 19 & $4.76 \mathrm{e}+00$ & 51 & 49 & 1 \\
\hline $\mathrm{C} 20: 1 \omega 9$ & $3.95 \mathrm{e}-01$ & 37 & 36 & 27 & $2.23 \mathrm{e}+00$ & 60 & 38 & 2 \\
\hline $\mathrm{C} 20: 3 \omega 6$ & $1.88 \mathrm{e}-01$ & 1 & 1 & 98 & $1.10 \mathrm{e}+00$ & 67 & 30 & 3 \\
\hline $\mathrm{C} 20: 4 \omega 6$ & $9.94 \mathrm{e}-02$ & 3 & 2 & 95 & $7.64 \mathrm{e}-02$ & 0 & 44 & 56 \\
\hline $\mathrm{C} 20: 5 \omega 3$ & $4.7 \mathrm{e}-01$ & 0 & 54 & 46 & $1.5 \mathrm{e}-01$ & 13 & 4 & 83 \\
\hline $\mathrm{C} 22: 6 \omega 3$ & $2.58 \mathrm{e}-01$ & 68 & 11 & 21 & $5.15 \mathrm{e}-01$ & 58 & 40 & 2 \\
\hline Total FA & $2.12 \mathrm{e}-01$ & 37 & 0 & 63 & $2.07 \mathrm{e}+00$ & 53 & 47 & 1 \\
\hline Total $\omega 9^{b}$ & $2.79 \mathrm{e}-01$ & 51 & 12 & 37 & $2.83 \mathrm{e}+00$ & 55 & 45 & 1 \\
\hline Total $\omega 3^{c}$ & $2.37 \mathrm{e}-01$ & 2 & 52 & 47 & $3.68 \mathrm{e}-01$ & 38 & 55 & 7 \\
\hline Total $\omega 6^{d}$ & $2.75 \mathrm{e}-01$ & 54 & 6 & 39 & $1.66 \mathrm{e}+00$ & 50 & 48 & 1 \\
\hline $\mathrm{C} 20: 5 \omega 3+\mathrm{C} 22: 6 \omega 3$ & $2.48 \mathrm{e}-01$ & 68 & 8 & 25 & $4.86 \mathrm{e}-01$ & 58 & 40 & 2 \\
\hline $\mathrm{C} 20: 3 \omega 6+\mathrm{C} 20: 4 \omega 6$ & $1.04 \mathrm{e}-01$ & 2 & 1 & 97 & $1.34 \mathrm{e}-01$ & 32 & 52 & 17 \\
\hline Total sat + mono $e$ & $1.94 \mathrm{e}-01$ & 12 & 10 & 78 & $2.52 \mathrm{e}+00$ & 54 & 46 & 0 \\
\hline
\end{tabular}

${ }^{a}$ Mean squared prediction error (MSPE) expressed as a coefficient of variation (cv). This value measures the distance between observed and predicted value. MSPE can be decomposed in central error $(\mathrm{CE})+$ regression error $(\mathrm{RE})+$ disturbance error (DE). CE describes the contribution of distance between mean values of observed and predicted data. The RE describes how the slope of the linear regression between predicted and observed data differs from one. DE is the remaining error. Fatty acid quantity is considered badly fitted if $\mathrm{DE} \leq$ $25 \%$; this values are written in bold font.

${ }^{b} \mathrm{C} 16: 1 \omega 9+\mathrm{C} 18: 1 \omega 9+\mathrm{C} 20: 1 \omega 9$

${ }^{c}$ Sum of C18:3w3, C20:5 $\omega 3, \mathrm{C} 22: 6 \omega 3$

${ }^{d}$ Sum of $\mathrm{C} 18: 2 \omega 6, \mathrm{C} 20: 3 \omega 6, \mathrm{C} 20: 4 \omega 6$

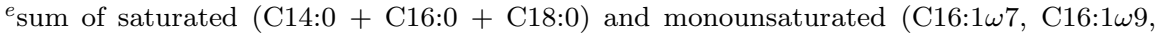
$\mathrm{C} 18: 1 \omega 7, \mathrm{C} 18: 1 \omega \mathrm{P})$ fatty acids. 
Table 6: MSPE coefficient of variation and its decomposition in the model 2 predicting fatty acids composition in mouse liver during fasting. This model includes fatty acid influx from adipose tissue and oxidation of fatty acids.

\begin{tabular}{|c|c|c|c|c|c|c|c|c|}
\hline \multirow{2}{*}{$\begin{array}{l}\text { Genotype } \\
\text { Statistics }\end{array}$} & \multicolumn{4}{|c|}{ PPAR $\alpha$ knock out mice } & \multicolumn{4}{|c|}{ Wild type mice } \\
\hline & $\operatorname{cvMSPE}^{a}$ & $\mathrm{CE}(\%)$ & $\operatorname{RE}(\%)$ & $\mathrm{DE}(\%)$ & cvMSPE & $\mathrm{CE}(\%)$ & $\mathrm{RE}(\%)$ & $\mathrm{DE}(\%)$ \\
\hline $\mathrm{C} 14: 0$ & $2.77 \mathrm{e}-01$ & 0 & 24 & 76 & $3.18 \mathrm{e}-01$ & 0 & 10 & 90 \\
\hline C16:0 & $3.16 \mathrm{e}-01$ & 6 & 57 & 37 & $2.52 \mathrm{e}-01$ & 3 & 46 & 51 \\
\hline C16:1 $1 \omega 9$ & $\begin{array}{l}3.10 \mathrm{e}-01 \\
2.52 \mathrm{e}-01\end{array}$ & 0 & 13 & 87 & $3.15 \mathrm{e}-01$ & 4 & $\begin{array}{l}40 \\
11\end{array}$ & 85 \\
\hline $\mathrm{C} 16: 1 \omega 7$ & $7.73 \mathrm{e}-01$ & 12 & 60 & 28 & $4.07 \mathrm{e}-01$ & 0 & 31 & 69 \\
\hline C18:0 & $1.35 \mathrm{e}-01$ & 34 & 5 & 60 & $7.75 \mathrm{e}-02$ & 9 & 1 & 90 \\
\hline C18:1 $\omega 9$ & $2.86 \mathrm{e}-01$ & 53 & 11 & 36 & $2.3 \mathrm{e}-01$ & 0 & 0 & 100 \\
\hline $\mathrm{C} 18: 1 \omega 7$ & $2.22 \mathrm{e}-01$ & 43 & 4 & 53 & $1.97 \mathrm{e}-01$ & 0 & 15 & 84 \\
\hline $\mathrm{C} 18: 2 \omega 6$ & $2.91 \mathrm{e}-01$ & 55 & 7 & 38 & $2.11 \mathrm{e}-01$ & 0 & 5 & 95 \\
\hline C18:3w3 & $6.62 \mathrm{e}-01$ & 13 & 67 & 19 & $3.74 \mathrm{e}-01$ & 0 & 23 & 76 \\
\hline $\mathrm{C} 20: 1 \omega 9$ & $3.95 \mathrm{e}-01$ & 37 & 36 & 27 & $3.51 \mathrm{e}-01$ & 1 & 23 & 76 \\
\hline $\mathrm{C} 20: 3 \omega 6$ & $1.88 \mathrm{e}-01$ & 1 & 1 & 98 & $1.28 \mathrm{e}-01$ & 23 & 4 & 73 \\
\hline $\mathrm{C} 20: 4 \omega 6$ & $9.94 \mathrm{e}-02$ & 3 & 2 & 95 & $7.16 \mathrm{e}-02$ & 11 & 24 & 65 \\
\hline C20:5 53 & $4.7 \mathrm{e}-01$ & 0 & 54 & 46 & $1.5 \mathrm{e}-01$ & 13 & 4 & 83 \\
\hline $\mathrm{C} 22: 6 \omega 3$ & $2.58 \mathrm{e}-01$ & 68 & 11 & 21 & $5.15 \mathrm{e}-01$ & 58 & 40 & 2 \\
\hline Total FA & $2.12 \mathrm{e}-01$ & 37 & 0 & 63 & $1.80 \mathrm{e}-01$ & 3 & 5 & 91 \\
\hline Total $\omega 9^{b}$ & $2.79 \mathrm{e}-01$ & 51 & 12 & 37 & $2.31 \mathrm{e}-01$ & 0 & 1 & 99 \\
\hline Total $\omega 3^{c}$ & $2.37 \mathrm{e}-01$ & 2 & 52 & 47 & $4.01 \mathrm{e}-01$ & 62 & 32 & 5 \\
\hline Total $\omega 6^{d}$ & $2.75 \mathrm{e}-01$ & 54 & 6 & 39 & $1.81 \mathrm{e}-01$ & 0 & 6 & 93 \\
\hline $\mathrm{C} 20: 5 \omega 3+\mathrm{C} 22: 6 \omega 3$ & $2.48 \mathrm{e}-01$ & 68 & 8 & 25 & $4.86 \mathrm{e}-01$ & 58 & 40 & 2 \\
\hline $\mathrm{C} 20: 3 \omega 6+\mathrm{C} 20: 4 \omega 6$ & $1.04 \mathrm{e}-01$ & $\begin{array}{r}0 \\
2\end{array}$ & 1 & 97 & $7.28 \mathrm{e}-02$ & 13 & 28 & 58 \\
\hline Total sat + mono $e$ & $1.94 \mathrm{e}-01$ & 12 & 10 & 78 & $1.91 \mathrm{e}-01$ & 1 & 12 & 87 \\
\hline
\end{tabular}

${ }^{a} \mathrm{MSPE}, \mathrm{CE}, \mathrm{RE}$ and DE are defined in footnote ${ }^{a}$ of Table 5

${ }^{b} \mathrm{C} 16: 1 \omega 9+\mathrm{C} 18: 1 \omega 9+\mathrm{C} 20: 1 \omega 9$

${ }^{c}$ Sum of $\mathrm{C} 18: 3 \omega 3, \mathrm{C} 20: 5 \omega 3, \mathrm{C} 22: 6 \omega 3$

${ }^{d}$ Sum of $\mathrm{C} 18: 2 \omega 6, \mathrm{C} 20: 3 \omega 6, \mathrm{C} 20: 4 \omega 6$

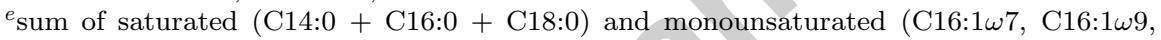
$\mathrm{C} 18: 1 \omega 7, \mathrm{C} 18: 1 \omega \mathrm{P})$ fatty acids.

Table 7: MSPE coefficient of variation and its decomposition in the model 3 predicting fatty acids composition in mouse liver during fasting. This model includes fatty acid influx from adipose tissue, oxidation of fatty acids and biosynthesis of polyunsaturated fatty acids.

\begin{tabular}{|c|c|c|c|c|c|c|c|c|}
\hline \multirow{2}{*}{$\begin{array}{l}\text { Genotype } \\
\text { Statistics }\end{array}$} & \multicolumn{4}{|c|}{ PPAR $\alpha$ knock out mice } & \multicolumn{4}{|c|}{ Wild type mice } \\
\hline & $\operatorname{cvMSPE}^{a}$ & $\mathrm{CE}(\%)$ & $\mathrm{RE}(\%)$ & $\mathrm{DE}(\%)$ & cvMSPE & $\mathrm{CE}(\%)$ & $\operatorname{RE}(\%)$ & $\mathrm{DE}(\%)$ \\
\hline C14:0 & $2.77 \mathrm{e}-01$ & 0 & 24 & 76 & $3.23 \mathrm{e}-01$ & 0 & 12 & 88 \\
\hline C16:0 & $3.16 \mathrm{e}-01$ & 6 & 57 & 37 & $2.47 \mathrm{e}-01$ & 5 & 42 & 53 \\
\hline $\mathrm{C} 16: 1 \omega 9$ & $2.52 \mathrm{e}-01$ & 0 & 13 & 87 & $3.17 \mathrm{e}-01$ & 3 & 12 & 85 \\
\hline $\mathrm{C} 16: 1 \omega 7$ & 7. $73 \mathrm{e}-01$ & 12 & 60 & 28 & $4 \mathrm{e}-01$ & 1 & 28 & 71 \\
\hline C18:0 & $1.35 \mathrm{e}-01$ & 34 & 5 & 60 & $7.96 \mathrm{e}-02$ & 13 & 3 & 84 \\
\hline $\mathrm{C} 18: 1 \omega 9$ & $2.86 \mathrm{e}-01$ & 53 & 11 & 36 & $2.31 \mathrm{e}-01$ & 0 & 1 & 99 \\
\hline $\mathrm{C} 18: 1 \omega 7$ & $2.22 \mathrm{e}-01$ & 43 & 4 & 53 & $1.93 \mathrm{e}-01$ & 2 & 11 & 87 \\
\hline $\mathrm{C} 18: 2 \omega 6$ & $2.91 \mathrm{e}-01$ & 55 & 7 & 38 & $2.09 \mathrm{e}-01$ & 1 & 3 & 96 \\
\hline $\mathrm{C} 18: 3 \omega 3$ & $4.41 \mathrm{e}-01$ & 0 & 56 & 44 & $5.08 \mathrm{e}-01$ & 56 & 1 & 44 \\
\hline $\mathrm{C} 20: 1 \omega 9$ & $3.95 \mathrm{e}-01$ & 37 & 36 & 27 & $3.57 \mathrm{e}-01$ & 1 & 26 & 74 \\
\hline $\mathrm{C} 20: 3 \omega 6$ & $1.88 \mathrm{e}-01$ & 1 & 1 & 98 & $1.30 \mathrm{e}-01$ & 28 & 3 & 69 \\
\hline $\mathrm{C} 20: 4 \omega 6$ & $9.94 \mathrm{e}-02$ & 3 & 2 & 95 & $7.25 \mathrm{e}-02$ & 6 & 30 & 64 \\
\hline $\mathrm{C} 20: 5 \omega 3$ & $4.7 \mathrm{e}-01$ & 0 & 54 & 46 & $1.5 \mathrm{e}-01$ & 13 & 4 & 83 \\
\hline $\mathrm{C} 22: 6 \omega 3$ & $1.40 \mathrm{e}-01$ & 14 & 16 & 70 & $1.19 \mathrm{e}-01$ & 51 & 20 & 29 \\
\hline Total FA & $2.12 \mathrm{e}-01$ & 37 & 0 & 63 & $1.80 \mathrm{e}-01$ & 3 & 5 & 91 \\
\hline Total $\omega 9^{b}$ & $2.79 \mathrm{e}-01$ & 51 & 12 & 37 & $2.33 \mathrm{e}-01$ & 0 & 2 & 98 \\
\hline Total $\omega 3^{c}$ & $2.37 \mathrm{e}-01$ & 2 & 52 & 47 & $1.68 \mathrm{e}-01$ & 60 & 8 & 33 \\
\hline Total $\omega 6^{d}$ & $2.75 \mathrm{e}-01$ & 54 & 6 & 39 & $1.8 \mathrm{e}-01$ & 1 & 4 & 95 \\
\hline $\mathrm{C} 20: 5 \omega 3+\mathrm{C} 22: 6 \omega 3$ & $1.50 \mathrm{e}-01$ & 12 & 20 & 68 & $1.17 \mathrm{e}-01$ & 51 & 17 & 32 \\
\hline $\mathrm{C} 20: 3 \omega 6+\mathrm{C} 20: 4 \omega 6$ & $1.04 \mathrm{e}-01$ & 2 & 1 & 97 & $7.34 \mathrm{e}-02$ & 9 & 33 & 57 \\
\hline Total sat + mono $e$ & $1.94 \mathrm{e}-01$ & 12 & 10 & 78 & $1.89 \mathrm{e}-01$ & 3 & 9 & 89 \\
\hline
\end{tabular}

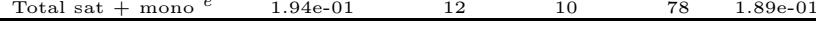

${ }^{a} \mathrm{MSPE}, \mathrm{CE}, \mathrm{RE}$ and DE are defined in footnote ${ }^{a}$ of Table 5

${ }^{b} \mathrm{C} 16: 1 \omega 9+\mathrm{C} 18: 1 \omega 9+\mathrm{C} 20: 1 \omega 9$

${ }^{c}$ Sum of $\mathrm{C} 18: 3 \omega 3, \mathrm{C} 20: 5 \omega 3, \mathrm{C} 22: 6 \omega 3$

${ }^{d}$ Sum of $\mathrm{C} 18: 2 \omega 6, \mathrm{C} 20: 3 \omega 6, \mathrm{C} 20: 4 \omega 6$

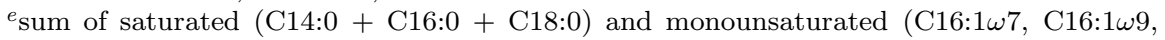
$\mathrm{C} 18: 1 \omega 7, \mathrm{C} 18: 1 \omega \mathrm{P})$ fatty acids. 
Figure 1: Pathways that influence fatty acid compositon in the liver. The main pathways influencing hepatic fatty acid quantities are indicated by streight arrows. AcetylCoenzyme A (AcoA) and malonyl-Coenzyme A (MalonylCoA) are pivots in hepatic intermediary metabolism. Transcriptional regulators of fatty acid synthesis, oxidation or desaturation are the sterol regulatory element binding transcription factor 1 (SREBP1) and peroxisome proliferator-activated receptor alpha $(\operatorname{PPAR} \alpha) .(+)$ signs for an activation, whereas $(-)$ signs for an inhibition of the pathway. During fasting, the pathways with a white cross are assumed to be inactive, and regulations marked with a black cross are assumed to have no direct influence on variations of fatty acid composition in the liver.

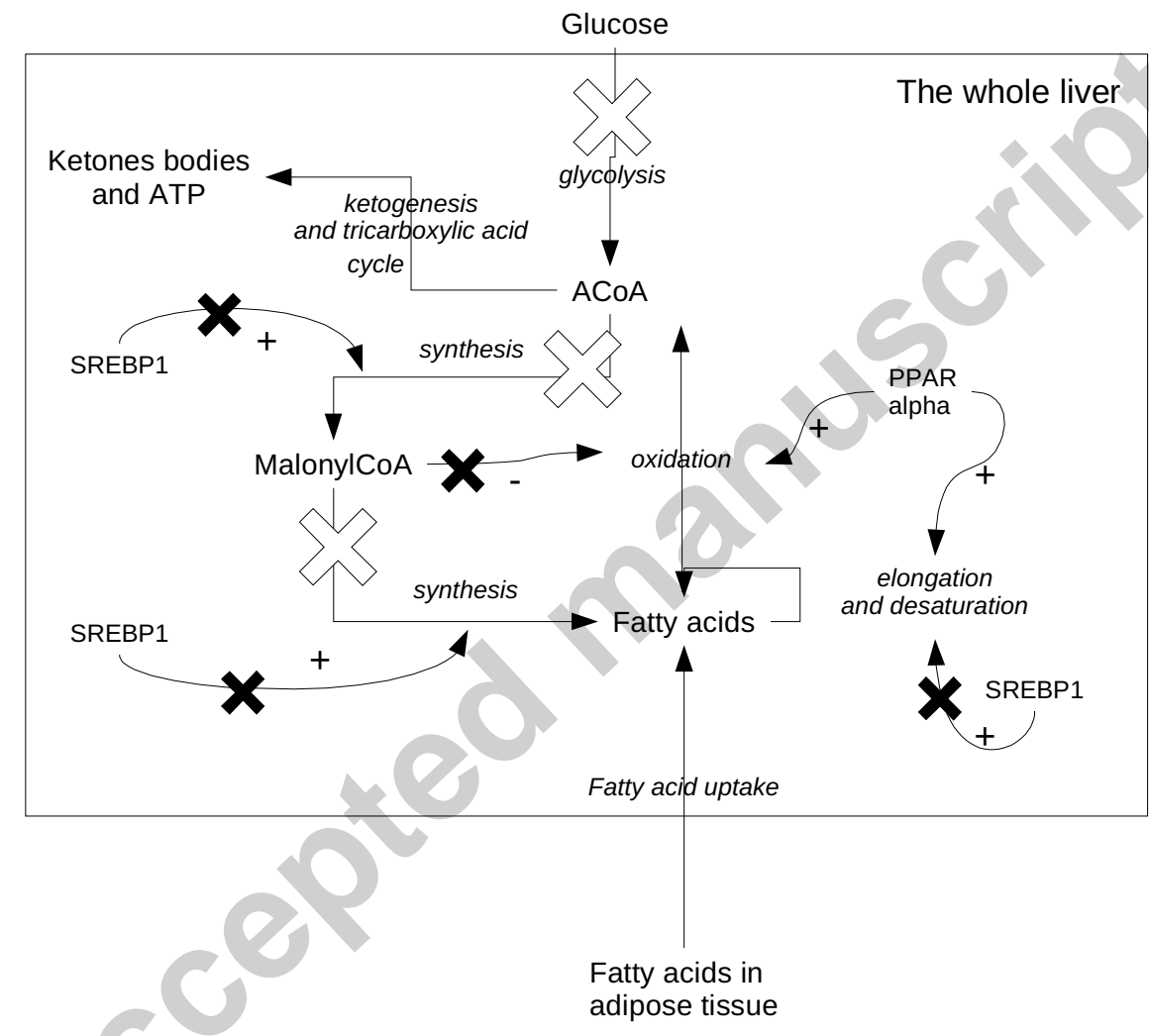


Figure 2: Transformations between fatty acids. Fatty acids are separated in 3 classes : saturated and monunsaturated, $\omega 6$, and $\omega 3$. The enzymes regulating desaturation and elongation are shown as delta-5-desaurase (D5D), delta-6-desaurase (D6D) and delta-9 desaurase (D9D). Reactions of interconvertion than occur only between fatty acids of a same class are represented by a solid line. The reactions allowing complete oxidation, importation, or synthesis of fatty acids from glucose are not shown.

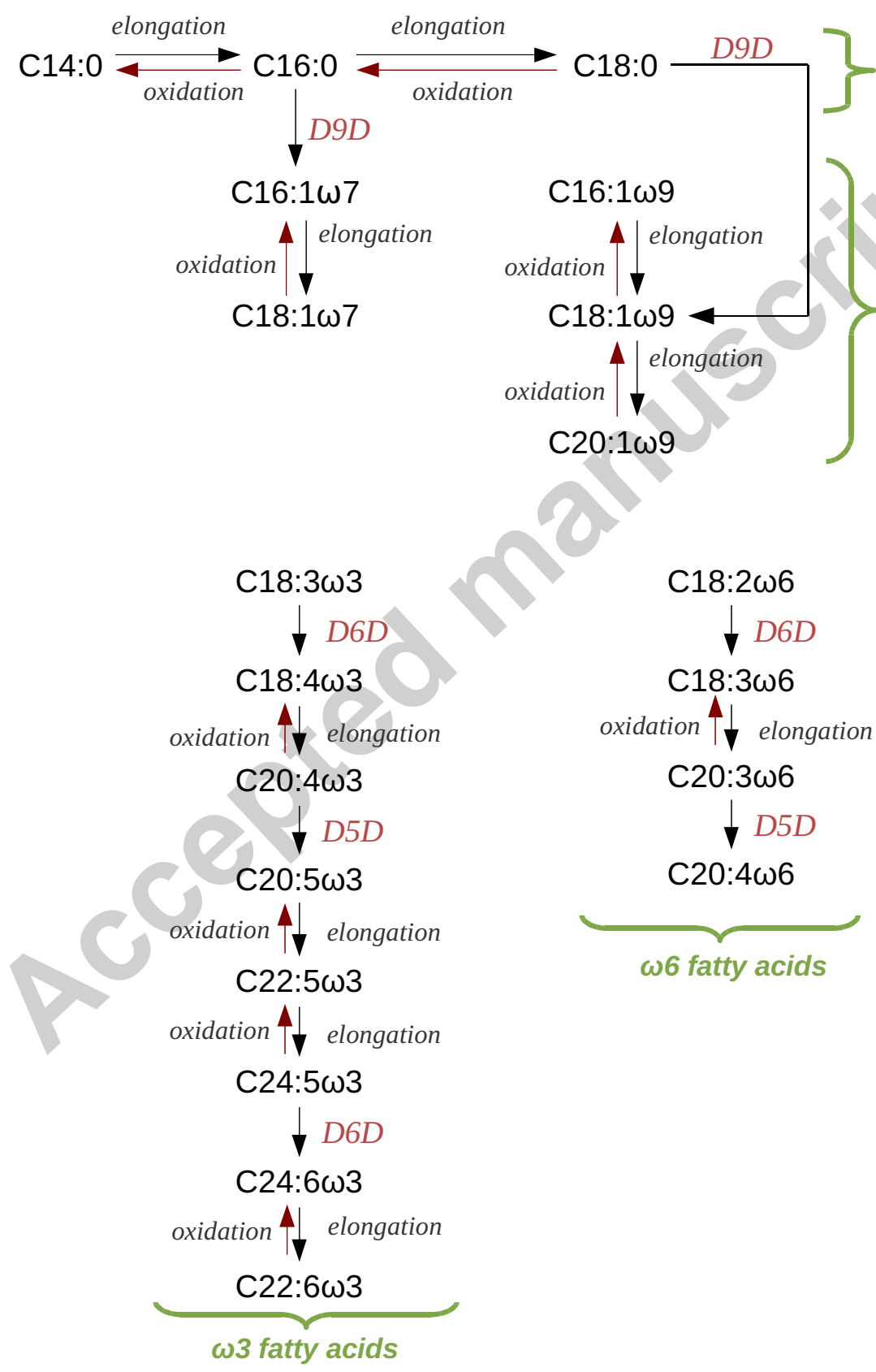


Figure 3: Models built for wild-type and PPAR $\alpha$ knockout (KO) mice according to a step-bystep procedure detailed in section 2.3. Model 1 included only fatty acides (FA) uptake from adiposite tissues (AT) to liver. Model 2 included both FA uptake and FA oxidation (oxi.) in liver. Model 3 was similar to model 2 but also included elongation and desaturation (elong. des.) of FA.
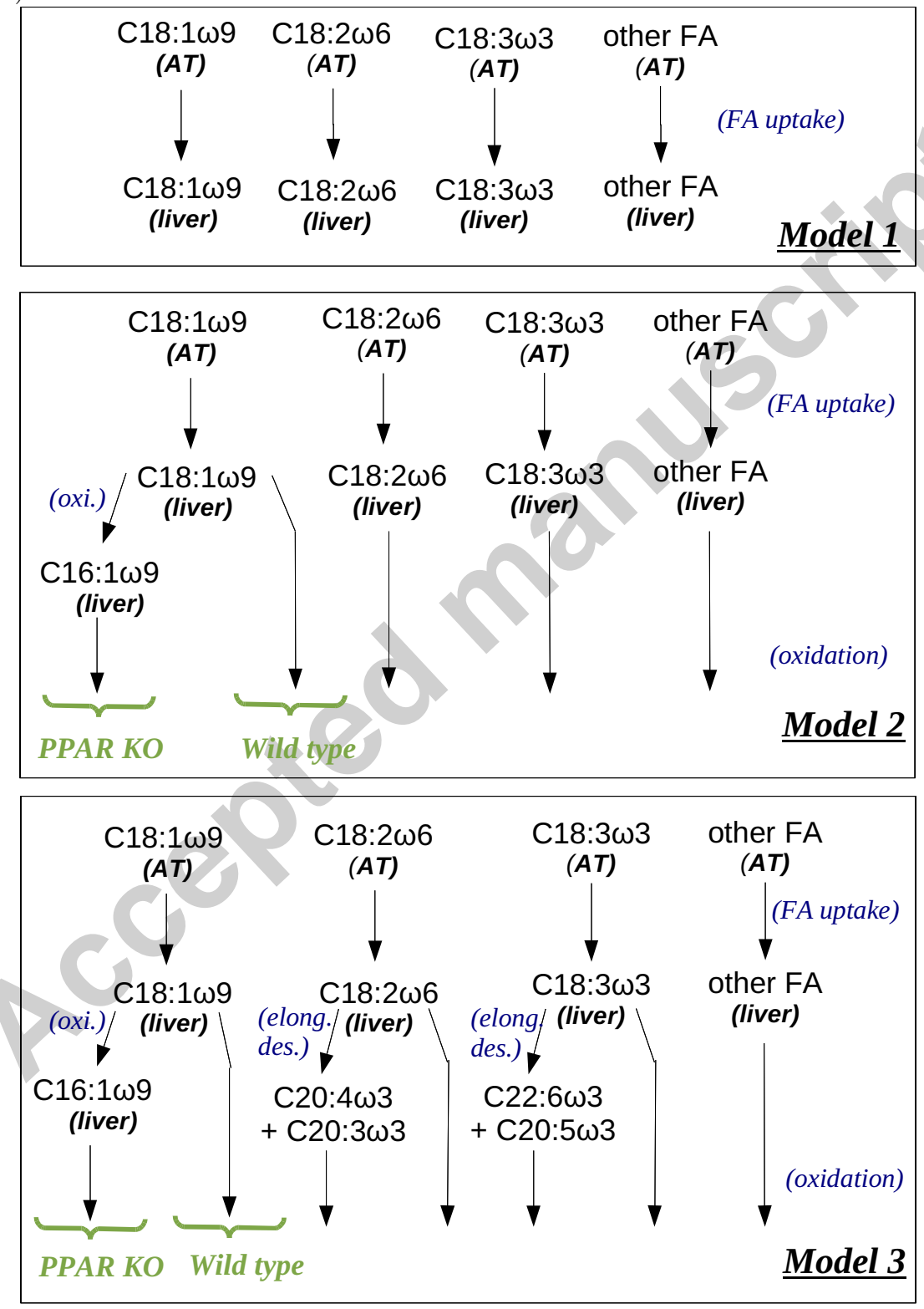
Figure 4: Measured mRNA of delta 6 deaturase in wild-type and PPAR $\alpha$ knockout mice liver during a $72 \mathrm{~h}$ fasting. The QPCR data were normalized by TATA-box binding protein (TBP) expression levels. ${ }^{a}$ indicates a significant difference (Student test, $p<0.05$ ) between the two genotypes at each time point and ${ }^{b}$ indicates a significant difference (Student test, $p<0.05$ ) since the onset of fasting. Error bars indicate the standard error of the mean.

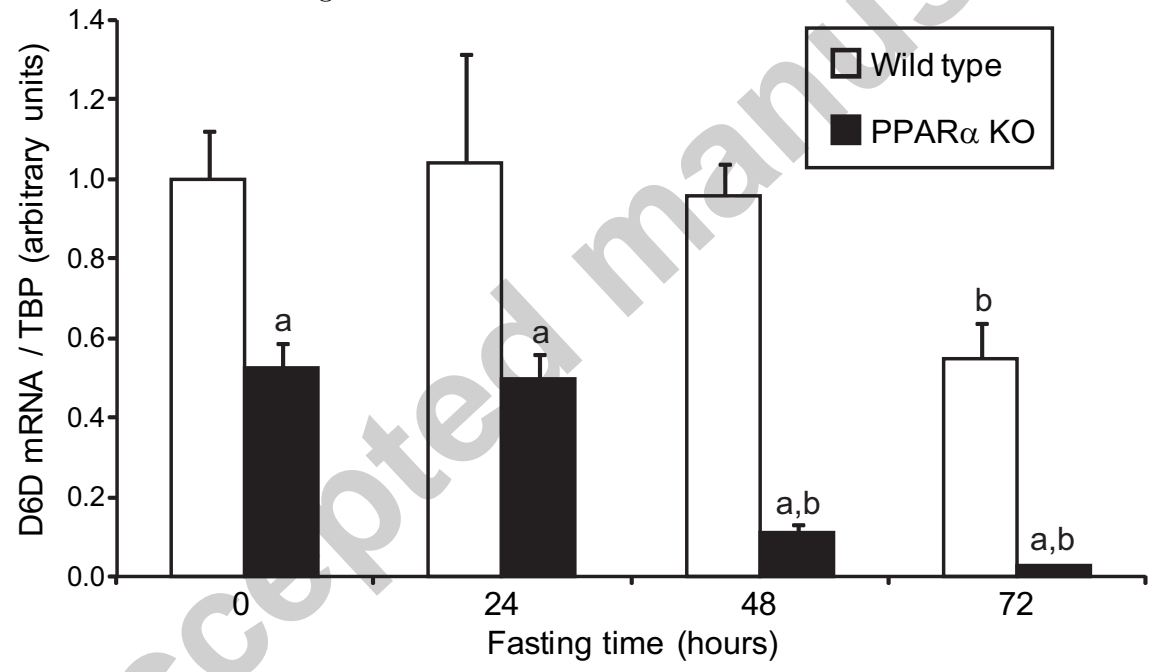


Figure 5: Predicted and observed quantities of fatty acids in the liver of wild type or PPAR $\alpha$ knockout (KO) mice during fasting.
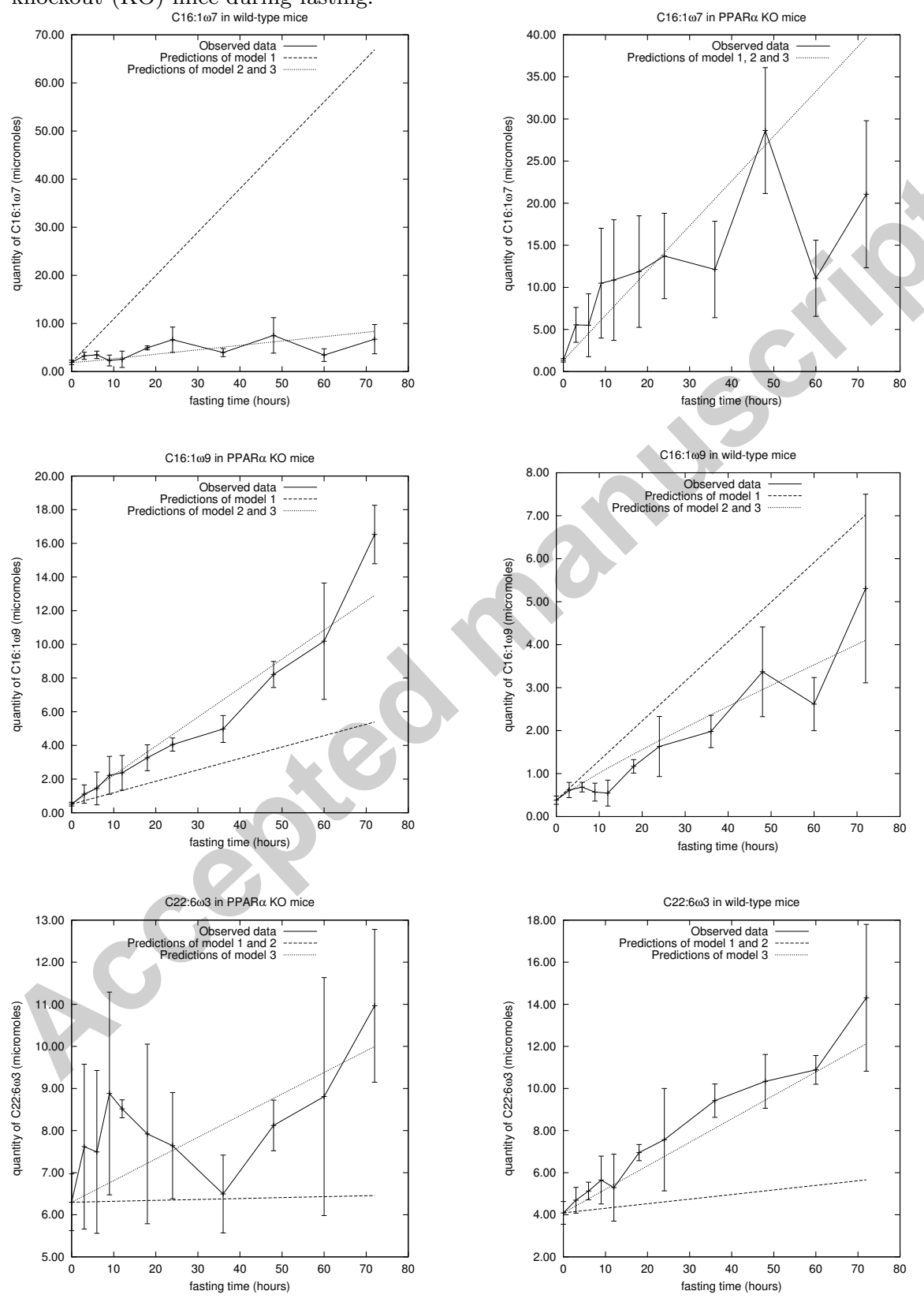